\title{
Safety of two common laparoscopic inguinal herniorrhaphy approaches: an updated systematic review with meta-analysis of randomized clinical trials
}

\author{
Tsung-Yu Hung ${ }^{1,2 \#}$, Chien-Chih Wu ${ }^{3,4 \#}$, Li-Siou Chen ${ }^{2,5}$, Yi-No Kang ${ }^{6,7,8,9}$ \\ ${ }^{1}$ Center for Evidence-Based Medicine, Department of Education, Taipei Medical University Hospital, Taipei; ${ }^{2}$ School of Medicine, College of \\ Medicine, Taipei Medical University, Taipei; ${ }^{3}$ Department of Urology, Taipei Medical University Hospital, Taipei; ${ }^{4}$ Department of Education and \\ Humanities in Medicine, School of Medicine, College of Medicine, Taipei Medical University, Taipei; ${ }^{5}$ Department of Physical Medicine and \\ Rehabilitation, Taipei Chang Gung Memorial Hospital, Taipei; ${ }^{6}$ Evidence-Based Medicine Center, Wan Fang Hospital, Taipei Medical University, \\ Taipei; ${ }^{7}$ Research Center of Big Data and Meta-analysis, Wan Fang Hospital, Taipei Medical University, Taipei; ${ }^{8}$ Cochrane Taiwan, Taipei Medical \\ University, Taipei; ${ }^{9}$ Institute of Health Policy and Management, College of Public Health, National Taiwan University, Taipei \\ Contributions: (I) Conception and design: CC Wu, YN Kang; (II) Administrative support: TY Hung; (III) Provision of study materials or patients: \\ TY Hung, LS Chen; (IV) Collection and assembly of data: TY Hung, LS Chen; (V) Data analysis and interpretation: CC Wu, YN Kang; (VI) \\ Manuscript writing: All authors; (VII) Final approval of manuscript: All authors. \\ \#These authors contributed equally to this work. \\ Correspondence to: Yi-No Kang, consultant. Evidence-Based Medicine Center, Wan Fang Hospital, Taipei Medical University, No. 111, Section 3, \\ Xing-Long Road, Taipei 11696. Email: academicnono@gmail.com.
}

Background: Previous evidence indicated that total extraperitoneal (TEP) and transabdominal preperitoneal (TAPP) are advantageous in efficacy of inguinal herniorrhaphy. Therefore, our aim in this study was to evaluate the association of the two laparoscopic approaches on safety of inguinal herniorrhaphy.

Methods: In this update study, we searched the Cochrane Library, EMBASE, PubMed, Scopus, and Web of Science and identified randomized clinical trials comparing complications in TEP and TAPP herniorrhaphy. We mainly used Peto odds ratio with 95\% confidence interval (CI) for meta-analysis because of zero-cell.

Results: Fourteen eligible trials recruited 659 and 682 patients in TEP and TAPP respectively. In overall pooling, although TEP had a higher seroma rate than TAPP (Peto odds ratio $=2.01 ; 95 \%$ CI, 1.39 to 2.91 ), it had a lower scrotal/cord edema rates at immediate postoperative (Peto odds ratio $=0.22 ; 95 \%$ CI, 0.09 to 0.57 ) and 1 week after inguinal hernia repair (Peto odds ratio $=0.58 ; 95 \% \mathrm{CI}, 0.37$ to 0.91 ) than TAPP.

Conclusions: TEP and TAPP have their own advantages in inguinal herniorrhaphy. TAPP was associated with a lower seroma rate, and TEP was associated with a lower edema rate. Therefore, shared decisionmaking on laparoscopic inguinal herniorrhaphy with TEP and TAPP is still needed.

Keywords: Totally extraperitoneal (TEP); transabdominal preperitoneal (TAPP); inguinal hernia; laparoscopic herniorrhaphy

Submitted Feb 23, 2020. Accepted for publication Aug 26, 2020.

doi: 10.21037/tau-20-629

View this article at: http://dx.doi.org/10.21037/tau-20-629

\section{Introduction}

Since laparoscopic herniorrhaphy was first introduced in the early 1990s, surgical technology and skills has been significantly developing $(1,2)$. Nowadays, laparoscopic herniorrhaphy has been widely accepted among both surgeons and patients because its success rate is comparable to open repair. Besides, laparoscopic herniorrhaphy has additional benefits such as less postoperative pain, less analgesic consumption, and shorter hospital stay $(1,3-10)$. Laparoscopic herniorrhaphy is usually performed 
through two major surgical approaches including totally extraperitoneal (TEP) and transabdominal preperitoneal (TAPP). Along with increasing popularity, considerable researches were performed focusing on efficacy and successful rate to determine the advantage between TEP and TAPP. Most previous studies on this topic claimed no significant difference in outcome (3,4,11-16). Two recent syntheses confirmed similar recurrence rates between the two laparoscopic herniorrhaphy approaches $(17,18)$. One of the two syntheses was the largest meta-analysis comparing TEP and TAPP with 16 randomized clinical trials (RCTs) from 17 references (18). The other one synthesis performed an advance method, network meta-analysis, to compare open, TEP, TAPP, and robotic preperitoneal repair though it only found five studies comparing TEP and TAPP directly (17). Their results about recurrence were low heterogeneity (I-square $=0 \%$ ). When TEP and TAPP showed comparable success rate with non-significant difference in recurrence rate $(3,4,11-16,18)$, safety and complications of each technique might provide decisive information on choice of technique.

Inguinal hernia has a high incidence and affects a large population; and therefore, even minor complications could cost considerable amount of extra resource. Unfortunately, complication rate after laparoscopic herniorrhaphy is about $10 \%$ (19), and no overview on complications between TEP and TAPP has been appropriately synthesized in previous systematic reviews and meta-analyses (16-18). In fact, several trials were performed to identify complication rates of TEP versus TAPP (5-12,14,20-24). They reported common intraoperative and postoperative complications including seroma, edema, hematoma, vascular injury, nerve injury, urinary retention, and wound infection. Yet, among these studies, diverting results have failed to obtain a consensus to which is the ideal technique. Moreover, relatively low complication rate might profoundly amplify the limitation of RCTs that involved small patient number, misleading to non-significant results. It is necessary to conduct a comprehensive synthesis about complications between TEP and TAPP, and the strong evidence-based study on complications of laparoscopic herniorrhaphy may provide precise and reasonable advice on choosing between TEP and TAPP. Thus, systematic reviews and meta-analysis should be further addressed to provide more strengthened results on this topic.

Two most recent systematic review and meta-analysis that discuss complication rate between TEP and TAPP was published in 2015 and 2019 (16,17). The synthesis in 2015 concluded that there was no significant difference in aspects of total complication, hematoma, seroma, analgesic consumption, urinary retention, hyperesthesia, cord edema, and wound infection between TAPP and TEP, but some of these results were highly heterogeneous (I-square $>50 \%$ ) (16). The other one similarly declared that TEP and TAPP seem comparable in term of hematoma, seroma, infectious complications, and urinary retention in short-term, but the authors also mentioned that their synthesis showed moderate-to-very low confidence, essentially due to study limitation, imprecision, and inconsistence (17). The two syntheses did not give reasons for excluding some important RCTs though they were the best evidence on safety of TEP and TAPP for herniorrhaphy now $(3,5,11,14,22,23)$. Thus, safety between the two laparoscopic herniorrhaphy approaches is still controversial though there were two syntheses making meta-analysis on relevant outcomes $(16,17)$. The purpose of our study is to include all current accessible evidence and perform a statistically comprehensive analysis to determine the difference in complications between TEP and TAPP for herniorrhaphy. All process and reports of this study followed PRISMA guideline (25) (available at http://dx.doi.org/10.21037/tau20-629).

\section{Methods}

Our research question in PICO format were:

* Patients/population: patients with inguinal hernia;

* Intervention: TEP;

* Comparator: TAPP,

* Outcome: complications.

According to the structured question, we defined eligible criteria, search terms, and search strategy. The protocol of our study has been registered in PROSPERO, and the registry number is CRD42017068992.

\section{Eligible criteria and evidence selection}

According to our PICO, we defined eligible criteria for evidence selection before evidence gathering, and the primary criteria were as follows: (I) RCT, (II) patients with inguinal hernia, and (III) comparison of TEP and TAPP. Then, we searched electronic databases without restriction on language and publication date from inception of each database to December 30, 2019. The databases were the Cochrane Library (including CENTER), EMBASE, PubMed, and Web of Science. The primary search strategy 
was built in PubMed by using relevant terms of hernia, TEP, and TAPP in both free text and medical subject heading (Supplementary File 1). We adapted the search strategy to the other databases with appropriate Boolean operators.

Two of us completed evidence selection after potential references were identified from electronic databases. Firstly, we removed duplicates and irrelevant references through title and abstract screening. Secondly, we retrieved fulltexts for those remaining references. Then, we reviewed the full-texts for selecting appropriate evidence according to eligible criteria. Another senior urologist participated in the process of evidence selection when the two authors had any inconsistency in judgement.

\section{Outcome definition and data extraction}

We did not restrict outcome at the beginning of this study. Two of us screened all the included trials for complications. Then, we identified relevant outcomes including seroma, edema, hematoma, intra-operative injury, urinary retention, epigastric vessel bleeding, and wound problem. These events were mentioned as main complications of laparoscopic herniorrhaphy in the target trials. The two authors double-checked the data before analysis. Our team members extracted not only the events for quantitative synthesis, but also trial characteristics for qualitative synthesis and quality assessment. The relevant information for quality synthesis involved area, sample size, sex, and hernia type. They also reviewed how the trials perform randomization, blinding, measurements, follow-up, analysis, and reporting outcomes.

\section{Quality assessment}

After the two authors extracted relevant information for quality assessment, we judged the risk of bias by using the Cochrane Risk of Bias Tool (26). The tool focuses on selection bias, performance bias, attrition bias, reporting bias, and other sources of bias. To reveal the five types of bias, we evaluated seven methodological items including: (I) random sequence generation, (II) allocation concealment, (III) blinding of participants and personnel, (IV) blinding of assessment, (V) incomplete outcome data, (VI) selective reporting, and (VII) other sources of bias. When the two authors had any inconsistency in quality assessment, another experienced researcher called a meeting for solving the disagreement by discussion.

\section{Statistical analysis}

Our work performed both qualitative synthesis and quantitative synthesis. About the quantitative synthesis, we applied pairwise meta-analysis in random-effects model. Because all our outcomes were binary data (complication rate), we planned to use risk ratio (RR). Yet, we used Peto odds ratio (POR) when any zero-cell existed in outcome. Pooled results were performed in effect size and $95 \%$ confidence interval (CI), and we judged no statistical difference between TEP and TAPP when $95 \%$ CI marginally cross or just fail to cross cut-point 1 . We planned to examine the quality of our pooled results through detections of heterogeneity and small study effects. The detection of heterogeneity in each pooled estimate used I-square. A pooled result should be considered as highly heterogeneous when I-square higher than $50 \%$. The detection of small study effects examined two common methods including funnel plot and Egger's regression intercept. A pooled result may not be seriously biased by small study effect when its funnel plot shows symmetric around the zero or its Egger's regression intercept is nonsignificant. Subgroup had been performed for primary inguinal hernia and involving recurrent inguinal hernia. We conducted pairwise meta-analysis in RevMan version 5.3 for Microsoft Windows and detected small study effects in Comprehensive Meta-Analysis version 2 for Microsoft Windows.

\section{Results}

After screening, 14 RCTs met eligible criteria (Figure 1). The 14 eligible trials recruited 1,341 patients with inguinal hernia and randomly assigned them into TEP $(n=659)$ and TAPP $(n=682)$. Most of these trials investigated males, and only seven trials reported that there were few females in their study population $(5,9-12,14,24)$. There were 10 trials only focused on primary inguinal hernia (7$9,11,12,14,20-22,24)$, and the other four trials did not mention about recurrent inguinal hernia in their exclusion criteria $(5,6,10,24)$. These trials usually covered both direct and indirect hernia, and there was only one trial targeted only direct hernia (8). Most trials included unilateral hernia and bilateral hernia $(5,6,10-12,14,20,23)$, and five of the included trials purely investigated unilateral hernia $(7,9,21,22,24)$. Table 1 showed relevant information of these trials, and quality of these trials was performed in Figure S1. Selection bias, performance bias, and attrition bias should be 


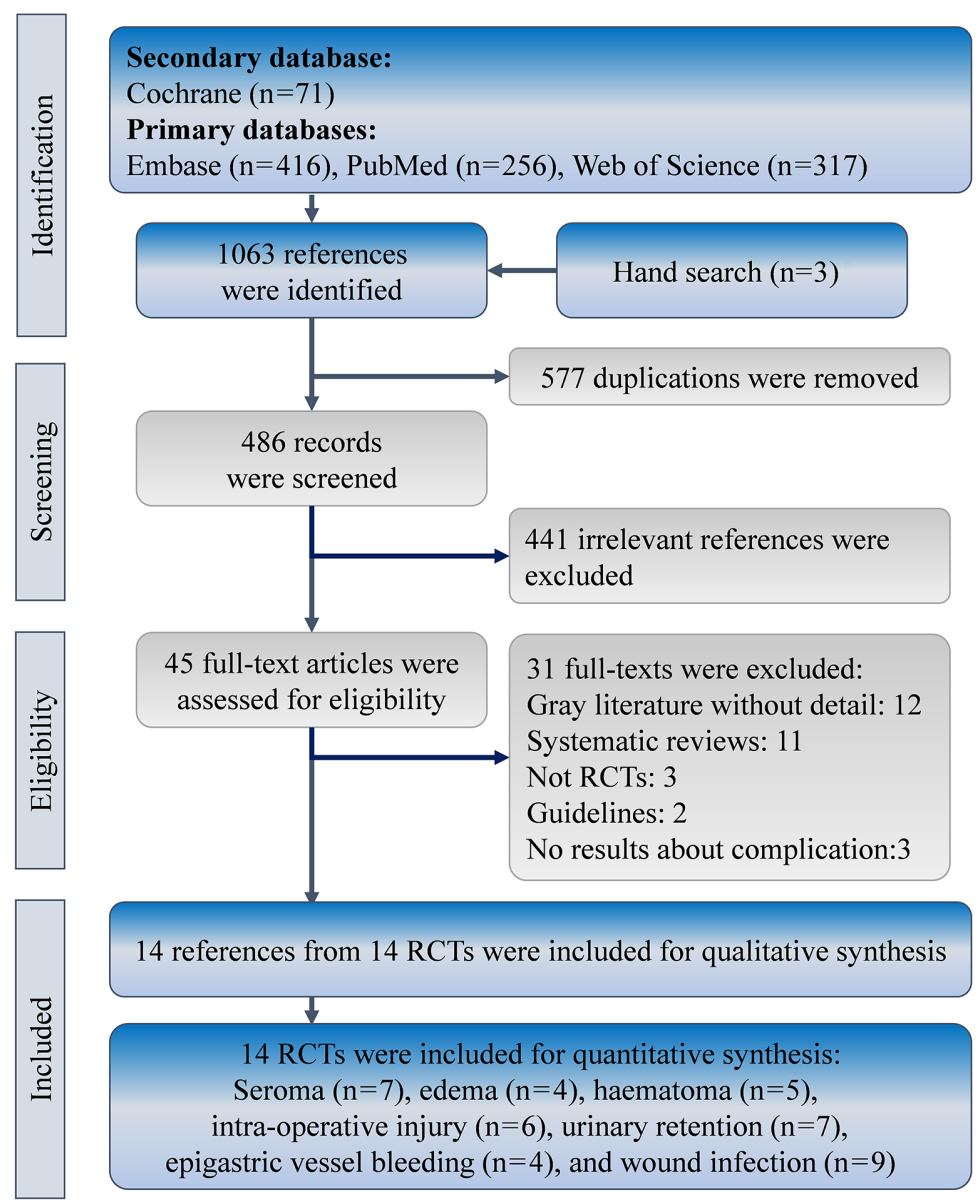

Figure 1 Flowchart of evidence selection. RCT, randomized clinical trial.

concerned due to insufficient information in randomization sequence and concealment, no blinding to health providers, and about $15 \%$ lost follow-up. However, many trials in this synthesis may be low risk of bias in detection and selected reporting.

\section{Seroma}

A total of seven trials $(n=882)$ reported seroma $(5,9,10,12,14,20,23)$, and four of the seven trials mainly focused on primary hernia repairment $(n=603)(9,12,14,20)$. Overall pooled results showed that TEP led to higher seroma rate than TAPP ( $\mathrm{POR}=2.01$; 95\% CI, 1.39 to 2.91; I-square $=9 \%$; Figure 2). Interestingly, we only observed similar result in subset of primary hernia cases $(\mathrm{POR}=2.19$; $95 \%$ CI, 1.45 to 3.31 ; I-square $=30 \%$ ), but TEP in subset for those trials involving patients with recurrent inguinal hernia did not lead to significantly higher seroma rate than TAPP (POR=1.42; 95\% CI, 0.63 to 3.24 ; I-square $=0 \%$ ). Egger's test did not detect serious small study bias in pooled result of seroma $($ Intercept $=0.123 ; \mathrm{P}=0.883 ;$ Figure 3$)$.

\section{Edema}

Four trials mentioned about edema $(9,11,12,20)$. Three of them reported scrotal/cord edema $(11,12,20)$, and the other trial mentioned about penis edema (Figure 4) (9). Pooled estimate showed that TEP resulted in lower scrotal/ cord edema rates at immediate postoperative $(\mathrm{POR}=0.22$; $95 \% \mathrm{CI}, 0.09$ to 0.57 ; I-square $=0 \%$ ) and 1 week after surgery $(\mathrm{POR}=0.58 ; 95 \% \mathrm{CI}, 0.37$ to 0.91 ; I-square $=91 \%)$. Although one trial mentioned about penis edema, it cannot 


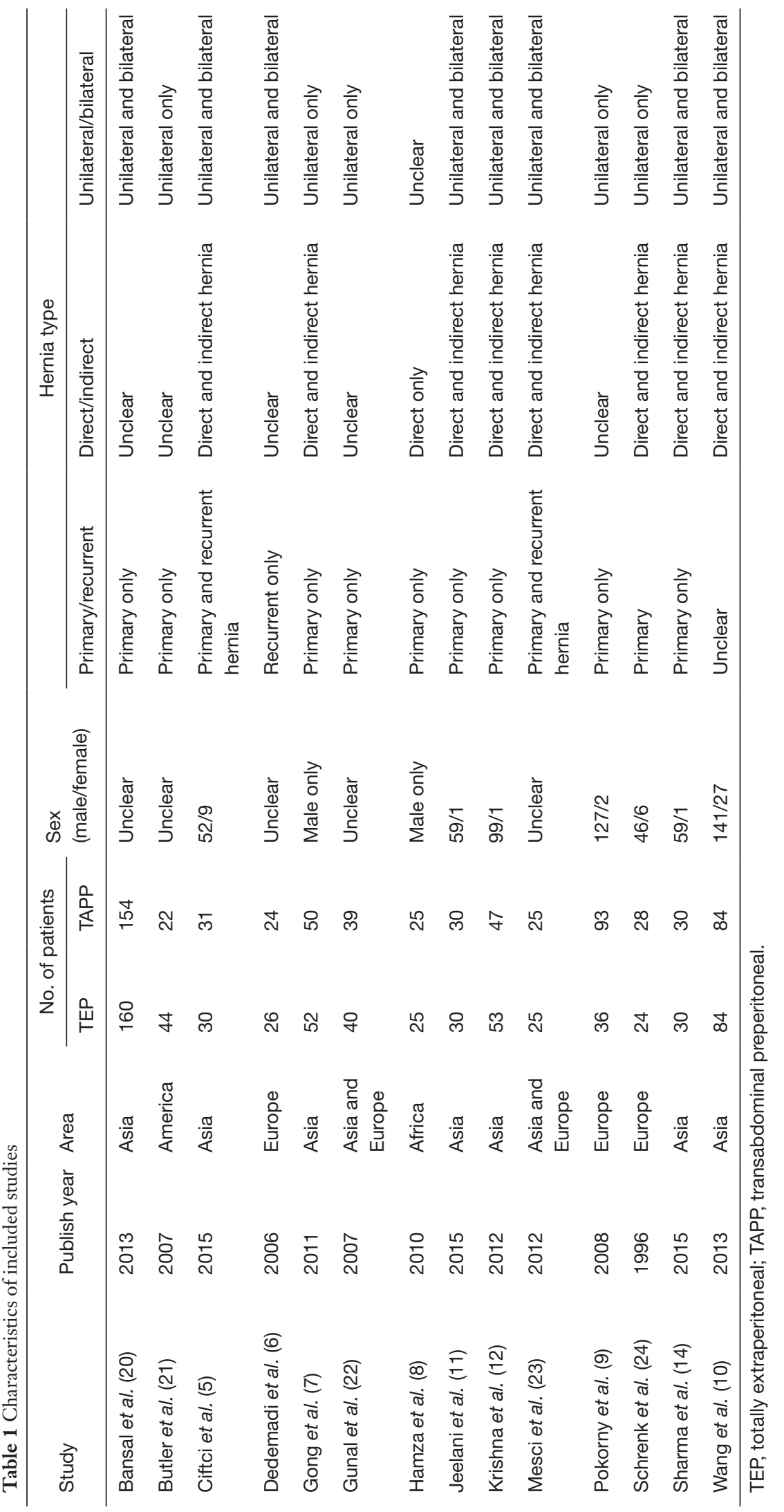


A

TEP TAPP

Peto Odds Ratio

Peto Odds Ratio

Study or Subgroup Events Total Events Total Weight Peto, Fixed, 95\% CI 1.1.1 Seroma (Patient with primary inguinal hernia)

\begin{tabular}{|c|c|c|c|c|c|c|}
\hline Pokorny et al 2008 & 1 & 36 & 7 & 93 & $5.4 \%$ & $0.44[0.09,2.18]$ \\
\hline Sharma et al 2015 & 4 & 30 & 2 & 30 & $4.9 \%$ & $2.07[0.39,11.04]$ \\
\hline Bansal et al 2013 & 52 & 160 & 25 & 154 & $51.6 \%$ & $2.40[1.44,4.01]$ \\
\hline Krishna et al 2012 & 20 & 53 & 8 & 47 & $18.0 \%$ & $2.77[1.16,6.60]$ \\
\hline Subtotal $(95 \% \mathrm{CI})$ & & 279 & & 324 & $79.9 \%$ & $2.19[1.45,3.31]$ \\
\hline Total events & 77 & & 42 & & & \\
\hline \multicolumn{7}{|c|}{ Heterogeneity: $\mathrm{Chi}^{2}=4.27, \mathrm{df}=3(\mathrm{P}=0.23) ; \mathrm{I}^{2}=30 \%$} \\
\hline \multicolumn{7}{|c|}{ Test for overall effect: $\mathrm{Z}=\mathbf{3 . 7 3}(\mathrm{P}=0.0002)$} \\
\hline
\end{tabular}

1.1.2 Seroma (Involving patient with recurrent inguinal hernia)

$\begin{array}{lrrrrrr}\text { Wang et al 2013 } & 13 & \mathbf{8 4} & 11 & 84 & \mathbf{1 8 . 3 \%} & 1.21[0.51,2.87] \\ \text { Mesci et al 2012 } & 1 & 25 & 0 & 25 & 0.9 \% & 7.39[0.15,372.38] \\ \text { Ciftci et al 2015 } & 1 & 30 & 0 & 31 & 0.9 \% & 7.64[0.15,385.21] \\ \text { Subtotal (95\% CI) } & & \mathbf{1 3 9} & & \mathbf{1 4 0} & \mathbf{2 0 . 1 \%} & \mathbf{1 . 4 2}[\mathbf{0 . 6 3}, \mathbf{3 . 2 4}] \\ \text { Total events } & 15 & & 11 & & & \end{array}$

Total events

15

11

Heterogeneity: $\mathrm{Chi}^{2}=1.52, \mathrm{df}=2(\mathrm{P}=0.47) ; \mathrm{I}^{2}=0 \%$

Test for overall effect: $\mathrm{Z}=0.84(\mathrm{P}=0.40)$

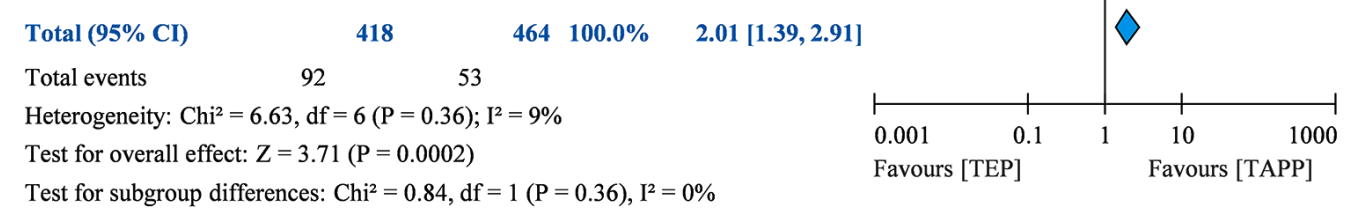

B

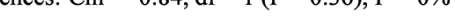

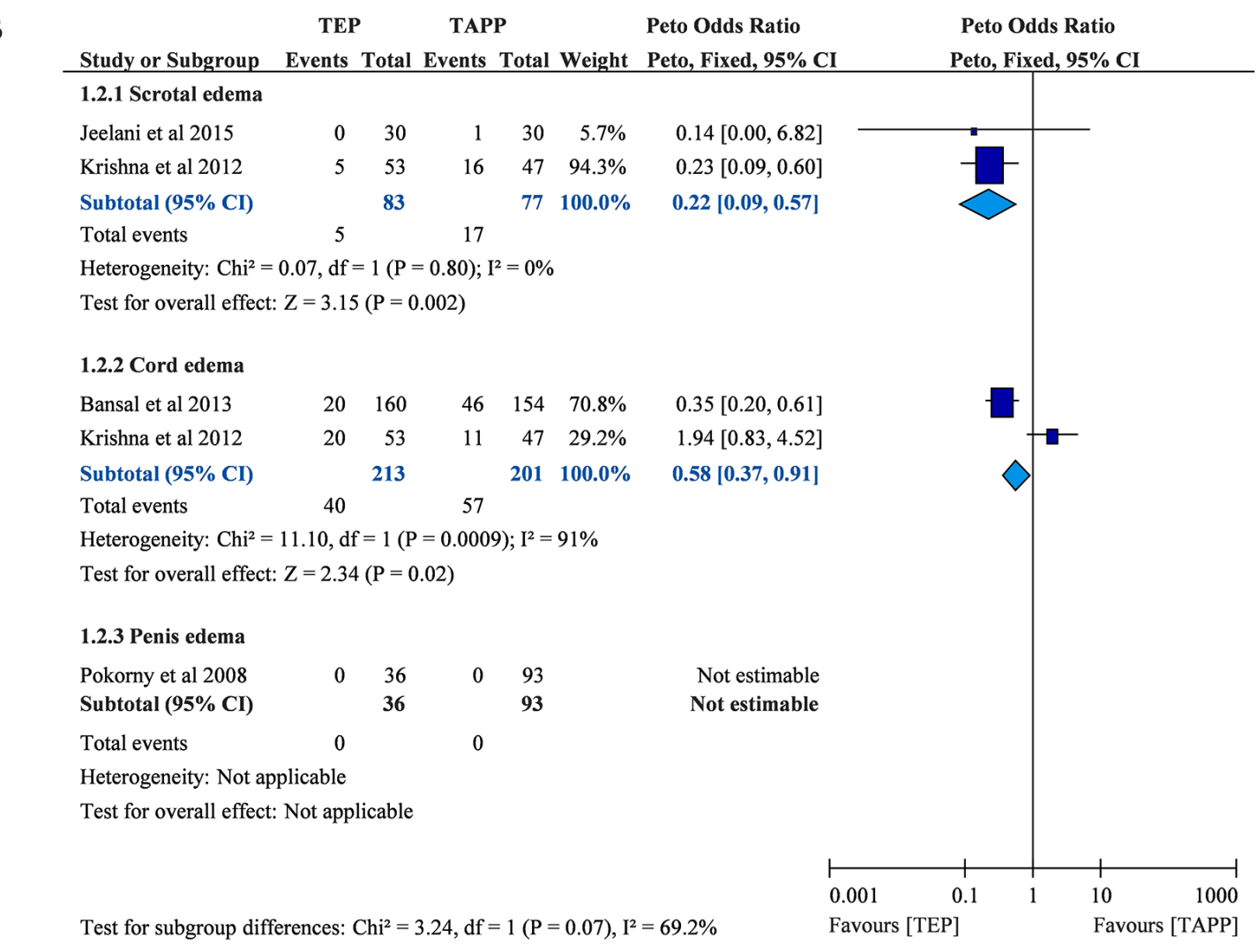

Figure 2 Forest plots of seroma. 


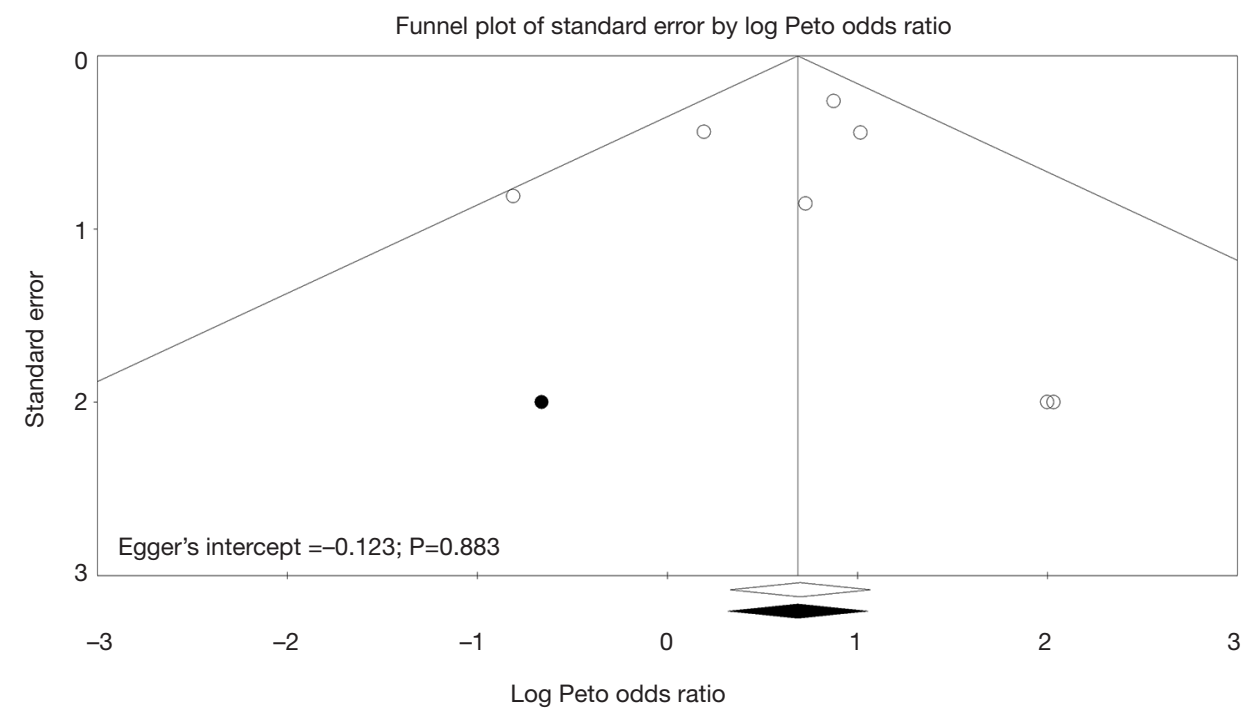

Figure 3 Funnel plot of seroma.

be analysed because of no penis edema in both TEP and TAPP groups. Unfortunately, this outcome had insufficient data for detecting small study bias.

\section{Haematoma}

Although there were five trials $(\mathrm{n}=383)$ reported haematoma $(7-9,23,24)$, four of them contributed to the pooled analysis (Table 2; Figure S2) (7-9,24). The other one trial cannot be estimated in meta-analysis because the trial reported no haematoma in both TEP and TAPP groups (23). Overall pooling was based on primary inguinal hernia data, and the result showed that TEP and TAPP had similar haematoma rate $(\mathrm{POR}=0.83 ; 95 \% \mathrm{CI}, 0.25$ to 2.75 ; I-square $=22 \%$ ). Egger's test did not detect serious small study bias in pooled result of haematoma (Intercept $=-0.581 ; \mathrm{P}>0.05$; Figure S3).

\section{Intra-operative injury}

Although there were six eligible trials mentioned about intra-operative injury rate $(\mathrm{n}=451)(6,9,11,12,14,24)$, there were only four trials contributed to meta-analysis of intraoperative injury $(\mathrm{n}=299)(6,9,11,14)$. Overall pooled result showed non-significant difference in intra-operative injury between TEP and TAPP (POR=0.71; 95\% CI, 0.22 to 2.28; I-square $=47 \%$; Figure S4). Similar trends can be observed in two subsets, and they were also non-significant results. Egger's test did not detect serious small study bias in pooled result of intra-operative injury (Intercept $=0.809 ; \mathrm{P}>0.05$; Figure S5).

\section{Urinary retention}

There were seven included trials $(\mathrm{n}=531)$ presented data on urinary retention $(5-7,9,11,22,23)$. Four of the seven trials only recruited patients with primary hernia $(\mathrm{n}=370)$ $(7,9,11,22)$. Overall pooling showed similar urinary retention rates between TEP and TAPP $(\mathrm{POR}=1.15$; 95\% CI, 0.49 to 2.69; I-square $=0 \%$; Figure S6). Subset of primary hernia (POR=1.15; 95\% CI, 0.49 to 2.69; I-square $=0 \%$ ) and subset involving patients with recurrent inguinal hernia (POR=1.75; 95\% CI, 0.66 to 4.64; I-square $=0 \%$ ) also presented non-significant differences in urinary retention between the two laparoscopic herniorrhaphy approaches. Egger's test did not detect serious small study bias in pooled result of urinary retention (Intercept $=-1.978$; $\mathrm{P}>0.05$; Figure S7).

\section{Epigastric vessel bleeding}

There were only four trials mentioning about epigastric vessel bleeding $(n=289)(6,12,14,22)$, and one of the four trials reported no epigastric vessel bleeding in both TEP and TAPP groups (12). Three of them focused on primary inguinal hernia, and the other one investigated recurrent inguinal hernia (6). Overall pooling result showed that TEP and TAPP had similar epigastric vessel bleeding rates $(\mathrm{POR}=0.98 ; 95 \% \mathrm{CI}, 0.28$ to 3.48 ; I-square $=16 \%$; Figure S8), and similarly subset of primary inguinal hernia ( $\mathrm{POR}=1.25 ; 95 \% \mathrm{CI}, 0.33$ to 4.76 ; I-square $=16 \%$ ) and 


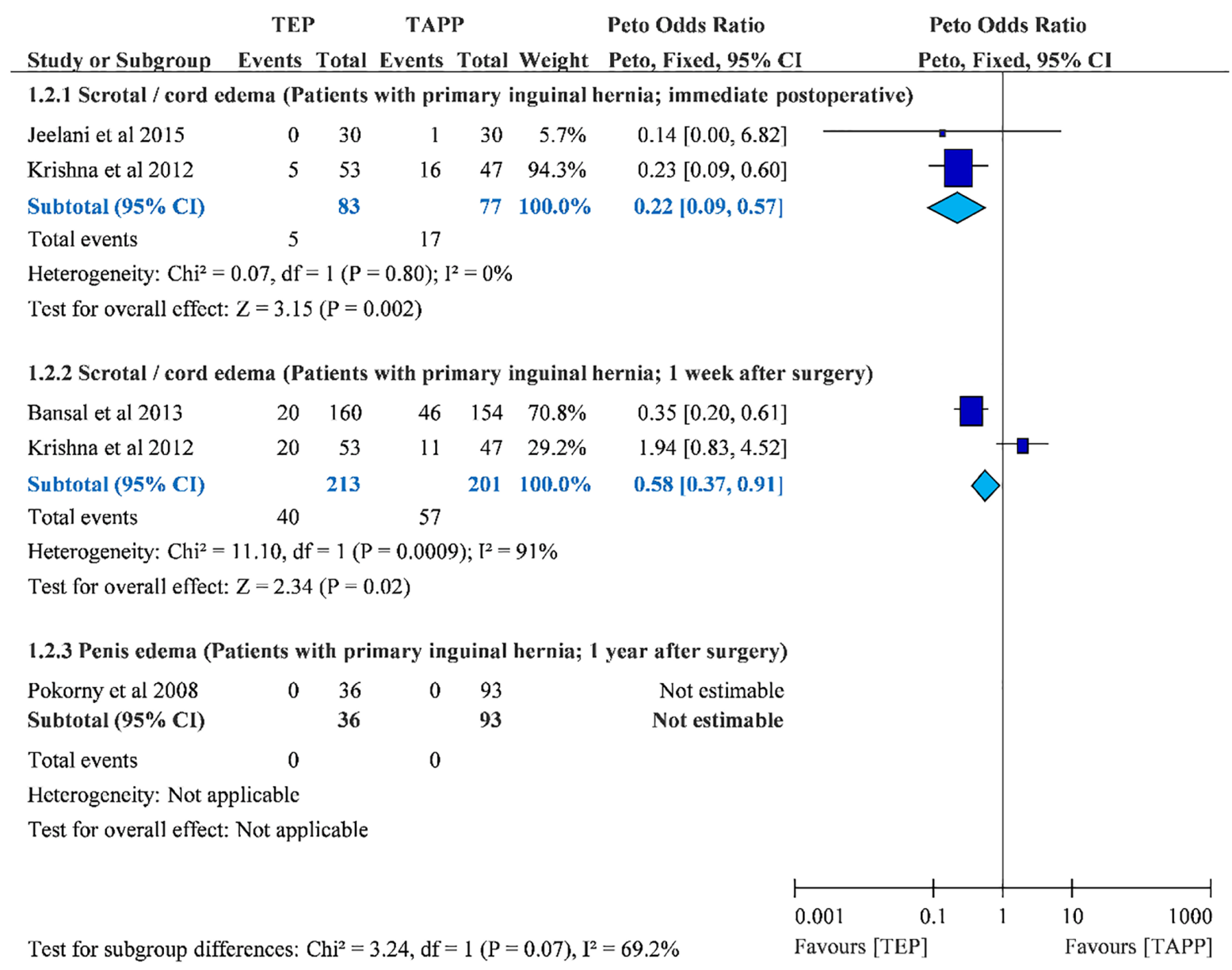

Figure 4 Forest plots of edema.

subset involving patients with recurrent inguinal hernia (POR $=0.12 ; 95 \%$ CI, 0.00 to 6.29 ) also showed nonsignificant results. Egger's test did not detect serious small study bias in pooled result of epigastric vessel bleeding (Intercept $=1.820 ; \mathrm{P}>0.05 ;$ Figure S9).

\section{Wound infection}

A total of nine eligible trials mentioned about wound infection rate $(\mathrm{n}=899)(6-9,12,14,20,21,23)$, but there were only five of them contributed to meta-analysis of wound infection $(n=626)(7,8,12,14,20)$. Because the other four trials presented no wound infection in both TEP and TAPP groups, these data cannot be estimated in metaanalysis $(5,6,9,21)$. Pooled result was only based on data from those with primary inguinal hernia, and the result showed TEP may lead to lower wound infection rate than
TAPP (POR=0.42; 95\% CI, 0.17 to $1.02 ;$ Figure S10). This result reached marginal significance and with very low heterogeneity (I-square $=0 \%$ ). Egger's test did not detect serious small study bias in pooled result of wound infection (Intercept $=-1.044 ; \mathrm{P}>0.05 ;$ Figure S11).

\section{Discussion}

\section{Key findings}

This systematic review and meta-analysis updated the safety of the two laparoscopic herniorrhaphy through synthesizing 14 RCTs with direct comparison of TEP and TAPP. The research identified and compared common complications including seroma, hematoma, urinary retention, scrotal and cord edema, wound infection, intra-operative injury, and epigastric vessel bleeding between the two laparoscopic 
Table 2 Outcome summary

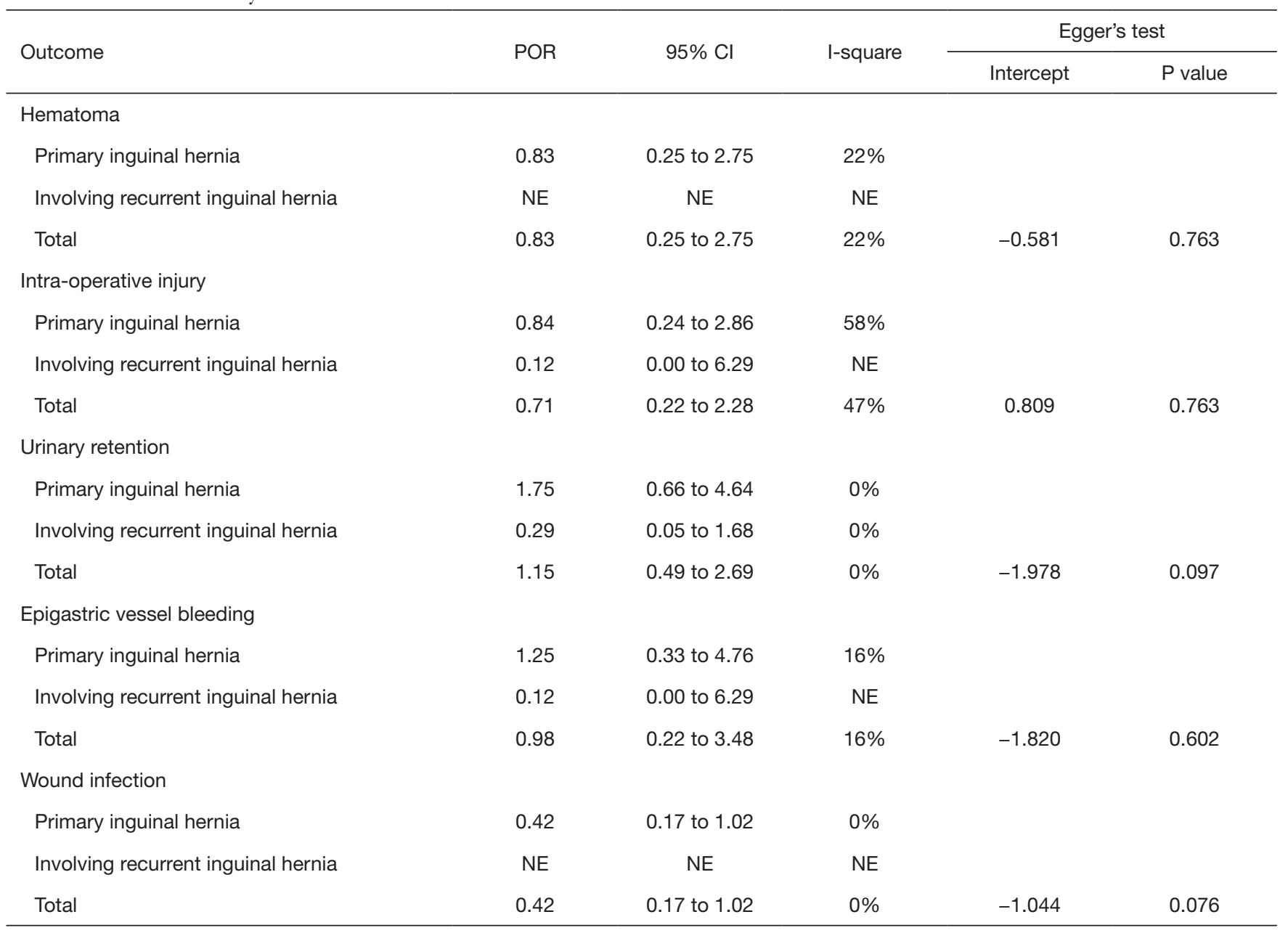

$\mathrm{Cl}$, confidence interval; NE, not estimate; POR, Peto odds ratio.

herniorrhaphy approaches. Although TEP and TAPP had similar risk in hematoma, urinary retention, wound infection, intra-operative injury, and epigastric vessel bleeding, they are advantageous in lowering two important complications. TEP had a lower risk of scrotal/cord edema, while TAPP had a lower risk of seroma formation in primary hernia population. TEP also showed a trend of lower wound infection rate in primary subgroup as comparing with TAPP though it just reached marginal significance in statistics. Summary of the main findings can be found in Table 3, and certainty of the evidence ranged from very low to moderate level according to the Grading of Recommendations Assessment, Development and Evaluation (GRADE) method (27).

About the two significant findings, seroma formation and scrotal/cord edema may impact clinical suggestions for laparoscopic herniorrhaphy. For seroma, we observed that TAPP had a lower risk of seroma formation in the subset of primary hernia population. To our knowledge, seroma formation was associated with extended surgeries and large amount of disrupted tissue (28). Because TAPP has more operation space and less complexity to surgeons, it might cause lesser tissue disrupted and may lead to lower risk of seroma formation. Several surgical modifications and advanced prosthetic materials were developed to decrease postoperative seroma formation. Modified TAPP with inversion of lax transversalis fascia by tacking it to the pubic ramus is associated with a statistically lower incidence of postoperative seroma (29). With regarding to prosthetic materials, a trial indicated that TAPP using titanized extralightweight polypropylene mesh significantly benefited in lesser seroma formation when it was compared to traditional 
Table 3 GRADE Summary of findings

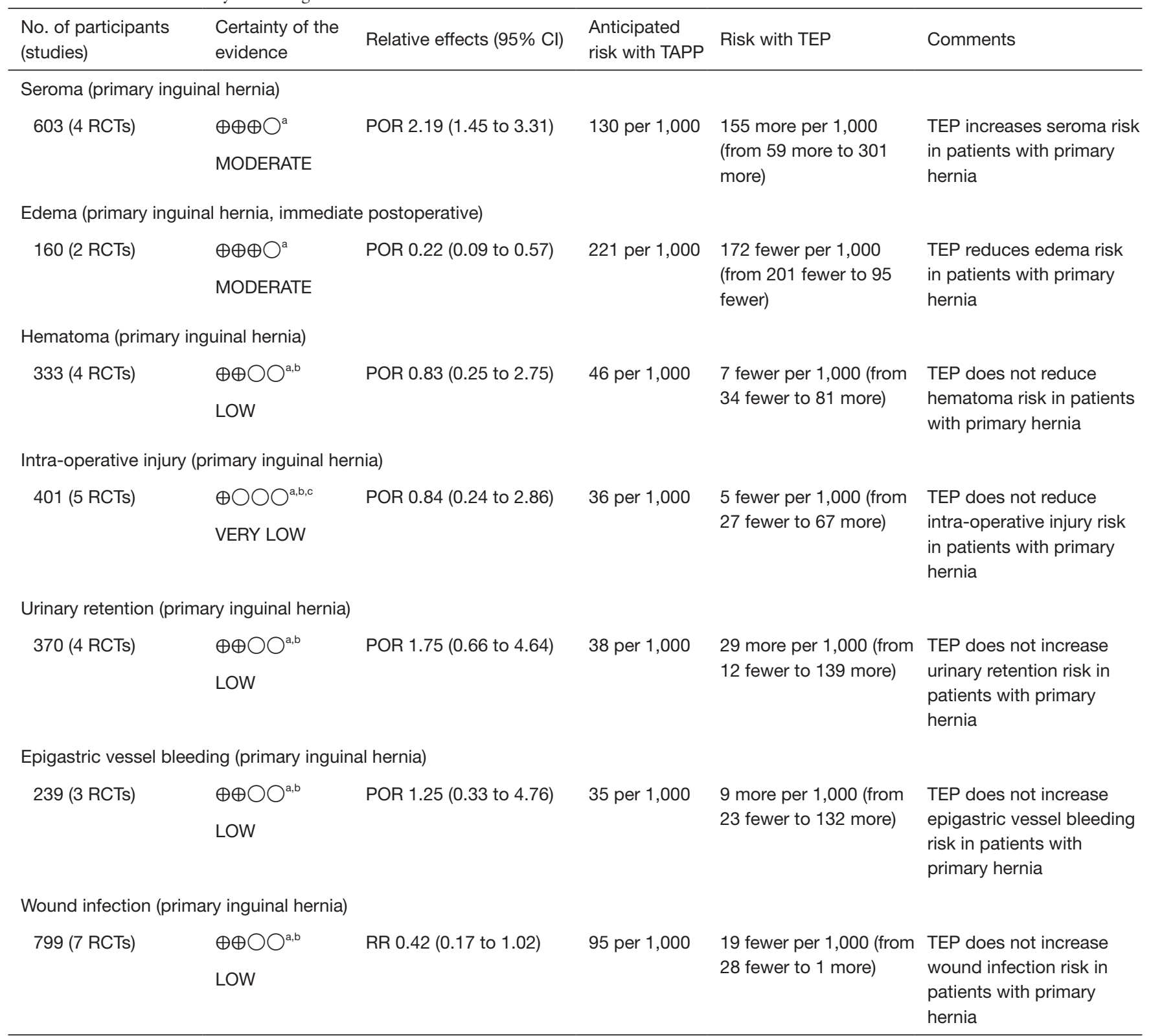

POR, Peto odds ratio; RCT, randomized controlled trial; TAPP, transabdominal preperitoneal; TEP, totally extraperitoneal. ${ }^{a}$ Downgrade a level due to high risk of bias in many trials. ${ }^{b}$ Downgrade a level due to wide range of confidence interval and relatively small sample size. ${ }^{c}$ Downgrade a level due to high heterogeneity (I-square $\left.>50 \%\right)$.

heavyweight mesh (30). Yet, other studies claimed that both mesh resulted in similar postoperative outcome in either long-term and short-term. Another factor, mesh fixation method, is hidden in this controversial phenomenon. A meta-analysis found that tissue glue had a lower incidence of seroma compared to suture fixation in laparoscopic inguinal herniorrhaphy (31). Thus, seroma formation after herniorrhaphy may be mainly due to laparoscopic approach, and may be contributed by mesh material and mesh fixation method.

For edema, inguinal hernia, particularly indirect type inguinal hernia, had a close anatomic relationship with genital structures (32). Consequently, inguinal hernia may present some genital structure complications. Because a 
higher tension on peritoneum easily causes compression to inguinal cord and contribute to genital structure edema, TAPP may easily lead to edema by damaging tissue and increasing tension on peritoneum. However, we hardly illustrated a clear picture of the mechanism for postoperative edema from insufficient evidence. Three of the 14 RCTs mentioned some patients with ischemic orchitis and testicular atrophy, but no further information of complication among those patients was reported $(11,12,20)$. The present evidence only showed a lower scrotal/cord edema rates in TEP than in TAPP. In the perspective of herniorrhaphy complication, furthermore, we cannot exclude the influence of mesh type, mesh fixation technique, and surgeon experience on genital edema though scant corresponding evidences on it. In clinical practice, it would be feasible to inform patients receiving TAPP about the higher risk of genital structure edema before we find more comprehensive evidences on postoperative edema and laparoscopic herniorrhaphy.

Hematoma formation was associated with intraoperative vessel injuries and untreated minor bleeding. With magnified visual field and advanced coagulation devices, laparoscopic herniorrhaphy has been reported to hold a significant lower risk of hematoma formation compared to open hernia repairs (33-35). However, the risk of both hematoma and intraoperative injury between TEP and TAPP in all subgroups was similar without statistical significance in this meta-analysis. All studies included in this meta-analysis failed to describe the location or severity of hematoma, possibly due to the lack of standardized diagnostic method and clinically relevant classification of hematoma. Furthermore, the coagulation status and anti-thrombotic medication usage of the patients were not analysed in these studies. Therefore, the influence of different methods of laparoscopic hernia repair on hematoma formation remained controversial and required a well-designed study for stronger evidence-based conclusion.

The risk of urinary retention between TEP and TAPP in all subgroups was similar without statistically significance. Anaesthesia methods had been a major concern of postoperative urinary retention (36). Although both TEP and TAPP were generally performed under general anaesthesia, different analgesic type and dosage significantly varied in urinary retention risk. Unfortunately, details of anaesthesia were not clearly mentioned in relevant trials (5-7,9,11,22,23). Intraoperative injury of genitourinary structures and associating nerves was also a possible cause of postoperative urinary retention. According to our study, intraoperative injury risk was similar between TEP and TAPP. Furthermore, the contribution of intraoperative injury to postoperative urinary retention might be limited by its relatively low incidence. Due to above features, it was reasonable that urinary retention risk between TEP and TAPP were comparable.

Wound infection has been a major concern ever since surgical intervention was introduced, which could cause longer hospital stay, higher cost, and might lead to severe morbidities in specific group of patients (37). Moreover, laparoscopic herniorrhaphy was generally performed with prosthetic meshes, and infection extended to prosthetic materials held a high risk of antibiotics resistance, which might inevitably require surgical revision for disease control. Due to above reasons, wound infection risk stood a critical role in clinical decision between different laparoscopic hernia repairs. In our study, although the result didn't reach statistical significance by a narrow margin, TEP showed a trend of lesser wound infection, holding less than half of the risk, compared to TAPP in primary hernia subgroup. Additional surgical damage and repair to peritoneum might contribute to additional risk of infection in TAPP, though specific cause was still uncertain. A study in 2015 concluded that laparoscopic herniorrhaphy had a lower risk of wound infection compared to open hernia repair. However, unlike open repair group, antibiotic prophylaxis did not provide significant impact on reducing wound infection rate in laparoscopic group (38). Previous study showed that whether mesh fixation was performed, or whether fixation was performed by staple or glue did not affect the wound infection rate in both TEP and TAPP (39-41). Despite that detailed information such as patient immune status, prophylactic antibiotic use, and postoperative wound management was not recorded in all studies; the heterogeneity of the result was very low (I-square $=0 \%$ ). According to the result, we believe it would be reasonable to perform TEP, instead of TAPP, especially on hernia patients vulnerable to or at high risk of infection, such as the, diabetes patients, elderlies and immunocompromised patients.

\section{Comparing to previous systematic review}

Comparing to the other synthesized evidences on this topic in past decades, the present evidence involved the greatest number of RCTs with direct comparison of TEP and TAPP $(16,17)$. Before our team investigated in this topic, there were five synthesized studies published between 2005 and 
2019. Two of them were published in four papers around 2005, and both studies included mostly retrospective case series because only one RCT on this topic were performed at that time $(13,15,34,42)$. One of the five syntheses was performed in 2012 by implementing indirect comparisons of TEP and TAPP through traditional open hernia repair (4). Although the meta-analysis found more RCTs than the two studies in 2005, it provided only indirect evidence from the RCTs of TEP versus open and TAPP versus open. Furthermore, it performed only limited result about complications. A synthesis in 2015 is the first metaanalysis using direct evidence of RCTs for comparing TEP with TAPP (16). It reported outcomes about complications, but the results were based on 1,047 patients from 10 RCTs. Heterogeneity in the results of complications should be concerned $(\mathrm{P}<0.10)$ according to the Cochrane handbook though the I-square in the meta-analysis was $43.1 \%$ (16). The Cochrane handbook recommended $\mathrm{P}$ value of 0.10 for determining the statistical significance in heterogeneity (43). The most recent synthesis in 2019 found TEP and TAPP had similar safety through network meta-analysis. However, its results were based on limited RCTs and retrospective studies. As a consequence, the authors admitted that a moderate-to-very low confidence in their results was due to study limitation, imprecision, and inconsistence (17). To improve the evidence on TEP and TAPP in herniorrhaphy, our study team has published a rigorous synthesis on this topic (18). In the present systematic review and metaanalysis, we followed similar methodological paradigm and kept the methodological strengths including a larger sample size, subset analysis of primary hernia, and appropriate statistics with POR. Then, we revealed an increased risk of seroma in TEP as comparing to TAPP and an increased risk of genital edema in TAPP as comparing to TEP. Our evidence was informative and reliable in the issue of safety between the two laparoscopic herniorrhaphy approaches.

\section{Limitations}

Although our study provided a stronger evidence, potential biases inevitably sustained within individual characteristics, study design, limited data of pooled studies, and clinical utilization. Clarifying these biases is important and may provide hints to evidence application and future researches on relevant topics. Firstly, we found a paucity of information about patients' characteristics in the 14 RCTs we included. For instance, few of them presented backward review on abdominal surgical history in TEP and TAPP separately.
For another example, body mass index may also affect complexity of surgery and clinical outcomes, but we did not see any detail about these associations. Besides, diseasespecific factors including severity, type, size, and location were important and may significantly affect complication rates. Unfortunately, the RCTs presented only part of these factors. To minimize the influence from disease factors, therefore, we can only identify the data from primary hernia and conducted subset analyses. The subset analysis successfully manifested some interesting findings. Yet, more accurate subgroup cannot be achieved in this meta-analysis due to the paucity of data.

Secondly, our study cannot exclude the variance from the various details in the treatments. For one, regarding to laparoscopic herniorrhaphy, these RCTs were reported between 1996 and 2015, through which surgical skills and equipment had been gradually developed. The diverse of techniques of laparoscopic herniorrhaphy involved video equipment, mesh materials, mesh fixations methods, and electro-cauterization settings in the past two decades. Moreover, surgeon experience had been reported to affect surgery duration and recurrence rate, and might consequently affect complication rate (16). Nevertheless, there was no clear cut to define surgeon experience, and we cannot overcome the impact from the surgeon experience. We completely agree with the declaration of the requirement for a clear statement about surgeon's skills in the relevant literature (16). For another, we did not find complete information of coagulation status and anti-thrombotic drug uses. As we know, anti-thrombotic drug may affect hematoma formation, while immunecompromised patients were prone to wound infections.

\section{Conclusions}

TEP and TAPP are advantageous in lowering risk of different complications. TEP had a lower risk of genital edema, while TAPP held a lower risk of seroma formation in patients with primary inguinal hernia. According to these evidence, laparoscopic herniorrhaphy in clinical practice still needs shared decision-making. It might be not necessary to spend time and money on identifying which herniorrhaphy approach leads to less complications, but it is better to take patients preference into consideration in the future. In other words, besides investigation of the efficacy and safety between TEP and TAPP, providing patients more information about benefits and risk of each laparoscopic herniorrhaphy and involving patients in decision-making 
on laparoscopic hernia repairment are important in clinical practice.

\section{Acknowledgments}

Funding: None.

\section{Footnote}

Reporting Checklist: The authors have completed the PRISMA reporting checklist. Available at http://dx.doi. org/10.21037/tau-20-629

Peer Review File: Available at http://dx.doi.org/10.21037/ tau-20-629

Conflicts of Interest: All authors have completed the ICMJE uniform disclosure form (available at http://dx.doi. org/10.21037/tau-20-629). The authors have no conflicts of interest to declare.

Ethical Statement: The authors are accountable for all aspects of the work in ensuring that questions related to the accuracy or integrity of any part of the work are appropriately investigated and resolved.

Open Access Statement: This is an Open Access article distributed in accordance with the Creative Commons Attribution-NonCommercial-NoDerivs 4.0 International License (CC BY-NC-ND 4.0), which permits the noncommercial replication and distribution of the article with the strict proviso that no changes or edits are made and the original work is properly cited (including links to both the formal publication through the relevant DOI and the license). See: https://creativecommons.org/licenses/by-nc-nd/4.0/.

\section{References}

1. Bittner R, Schwarz J. Inguinal hernia repair: Current surgical techniques. Langenbecks Arch Surg 2012;397:271-82.

2. Schultz L, Graber J, Pietrafitta J, et al. Laser laparoscopic herniorraphy: a clinical trial preliminary results. J Laparoendosc Surg 1990;1:41-5.

3. Bansal VK, Krishna A, Manek P, et al. A prospective randomized comparison of testicular functions, sexual functions and quality of life following laparoscopic totally extra-peritoneal (TEP) and trans-abdominal pre- peritoneal (TAPP) inguinal hernia repairs. Surg Endosc 2017;31:1478-86.

4. Bracale U, Melillo P, Pignata G, et al. Which is the best laparoscopic approach for inguinal hernia repair: TEP or TAPP? A systematic review of the literature with a network meta-analysis. Surg Endosc 2012;26:3355-66.

5. Ciftci F, Abdulrahman I, Ibrahimoglu F, et al. Early-Stage Quantitative Analysis of the Effect of Laparoscopic versus Conventional Inguinal Hernia Repair on Physical Activity. Chirurgia (Bucur) 2015;110:451-6.

6. Dedemadi G, Sgourakis G, Karaliotas C, et al. Comparison of laparoscopic and open tension-free repair of recurrent inguinal hernias: a prospective randomized study. Surg Endosc 2006;20:1099-104.

7. Gong K, Zhang N, Lu Y, et al. Comparison of the open tension-free mesh-plug, transabdominal preperitoneal (TAPP), and totally extraperitoneal (TEP) laparoscopic techniques for primary unilateral inguinal hernia repair: A prospective randomized controlled trial. Surg Endosc 2011;25:234-9.

8. Hamza Y, Gabr E, Hammadi H, et al. Four-arm randomized trial comparing laparoscopic and open hernia repairs. Int J Surg 2010;8:25-8.

9. Pokorny H, Klingler A, Schmid T, et al. Recurrence and complications after laparoscopic versus open inguinal hernia repair: Results of a prospective randomized multicenter trial. Hernia 2008;12:385-9.

10. Wang WJ, Chen JZ, Fang Q, et al. Comparison of the effects of laparoscopic hernia repair and lichtenstein tension-free hernia repair. J Laparoendosc Adv Surg Tech A 2013;23:301-5.

11. Jeelani S, Ahmad MS, Dar HM, et al. A comparative study of transabdominal preperitoneal verses totally extraperitoneal mesh repair of inguinal hernia. Appl Med Res 2015;1:57-61.

12. Krishna A, Misra MC, Bansal VK, et al. Laparoscopic inguinal hernia repair: Transabdominal preperitoneal (TAPP) versus totally extraperitoneal (TEP) approach: A prospective randomized controlled trial. Surg Endosc 2012;26:639-49.

13. McCormack K, Wake BL, Fraser C, et al. Transabdominal pre-peritoneal (TAPP) versus totally extraperitoneal (TEP) laparoscopic techniques for inguinal hernia repair: a systematic review. Hernia 2005;9:109-14.

14. Sharma D, Yadav K, Hazrah P, et al. Prospective randomized trial comparing laparoscopic transabdominal preperitoneal (TAPP) and laparoscopic totally extra peritoneal (TEP) approach for bilateral inguinal hernias. 
Int J Surg 2015;22:110-7.

15. Wake BL, McCormack K, Fraser C, et al. Transabdominal pre-peritoneal (TAPP) vs totally extraperitoneal (TEP) laparoscopic techniques for inguinal hernia repair. Cochrane Database Syst Rev 2005;(1):CD004703.

16. Wei FX, Zhang YC, Han W, et al. Transabdominal Preperitoneal (TAPP) Versus Totally Extraperitoneal (TEP) for Laparoscopic Hernia Repair: A Meta-Analysis. Surg Laparosc Endosc Percutan Tech 2015;25:375-83.

17. Aiolfi A, Cavalli M, Micheletto G, et al. Primary inguinal hernia: systematic review and Bayesian network metaanalysis comparing open, laparoscopic transabdominal preperitoneal, totally extraperitoneal, and robotic preperitoneal repair. Hernia 2019;23:473-84.

18. Chen LS, Chen WC, Kang YN, et al. Effects of transabdominal preperitoneal and totally extraperitoneal inguinal hernia repair: an update systematic review and meta-analysis of randomized controlled trials. Surg Endosc 2019;33:418-28.

19. HerniaSurge Group. International guidelines for groin hernia management. Hernia 2018;22:1-165.

20. Bansal VK, Misra MC, Babu D, et al. A prospective, randomized comparison of long-term outcomes: Chronic groin pain and quality of life following totally extraperitoneal (TEP) and transabdominal preperitoneal (TAPP) laparoscopic inguinal hernia repair. Surg Endosc 2013;27:2373-82.

21. Butler RE, Burke R, Schneider JJ, et al. The economic impact of laparoscopic inguinal hernia repair: Results of a double-blinded, prospective, randomized trial. Surg Endosc 2007;21:387-90.

22. Günal O, Ozer S, Gurleyik E, et al. Does the approach to the groin make a difference in hernia repair? Hernia 2007;11:429-34.

23. Mesci A, Korkmaz B, Dinckan A, et al. Digital evaluation of the muscle functions of the lower extremities among inguinal hernia patients treated using three different surgical techniques: a prospective randomized study. Surg Today 2012;42:157-63.

24. Schrenk P, Woisetschlager R, Rieger R, et al. Prospective randomized trial comparing postoperative pain and return to physical activity after transabdominal preperitoneal, total preperitoneal or Shouldice technique for inguinal hernia repair. Br J Surg 1996;83:1563-6.

25. Hutton B, Salanti G, Caldwell DM, et al. The PRISMA extension statement for reporting of systematic reviews incorporating network meta-analyses of health care interventions: checklist and explanations. Ann Intern Med
2015;162:777-84.

26. Higgins JP, Altman DG, Gotzsche PC, et al. The Cochrane Collaboration's tool for assessing risk of bias in randomised trials. BMJ 2011;343:d5928.

27. Guyatt G, Oxman AD, Akl EA, et al. GRADE guidelines: 1. Introduction-GRADE evidence profiles and summary of findings tables. J Clin Epidemiol 2011;64:383-94.

28. Cihan A, Ozdemir H, Ucan BH, et al. Fade or fate. Seroma in laparoscopic inguinal hernia repair. Surg Endosc 2006;20:325-8.

29. Reddy VM, Sutton CD, Bloxham L, et al. Laparoscopic repair of direct inguinal hernia: a new technique that reduces the development of postoperative seroma. Hernia 2007;11:393-6.

30. Bittner R, Schmedt CG, Leibl BJ, et al. Early postoperative and one year results of a randomized controlled trial comparing the impact of extralight titanized polypropylene mesh and traditional heavyweight polypropylene mesh on pain and seroma production in laparoscopic hernia repair (TAPP). World J Surg 2011;35:1791-7.

31. Shah NS, Fullwood C, Siriwardena AK, et al. Mesh fixation at laparoscopic inguinal hernia repair: a metaanalysis comparing tissue glue and tack fixation. World J Surg 2014;38:2558-70.

32. Townsend CM, Beauchamp RD, Evers BM, et al. Sabiston Textbook of Surgery E-Book: The Biological Basis of Modern Surgical Practice. Elsevier Health Sciences; 2016.

33. EU Hernia Trialists Collaboration. Laparoscopic compared with open methods of groin hernia repair: systematic review of randomized controlled trials. Br J Surg 2000;87:860-7.

34. McCormack K, Scott NW, Go PM, et al. Laparoscopic techniques versus open techniques for inguinal hernia repair. Cochrane Database Syst Rev 2003;(1):CD001785.

35. Schmedt CG, Sauerland S, Bittner R. Comparison of endoscopic procedures vs Lichtenstein and other open mesh techniques for inguinal hernia repair: a metaanalysis of randomized controlled trials. Surg Endosc 2005;19:188-99.

36. Koch CA, Grinberg GG, Farley DR. Incidence and risk factors for urinary retention after endoscopic hernia repair. Am J Surg 2006;191:381-5.

37. Mangram AJ, Horan TC, Pearson ML, et al. Guideline for Prevention of Surgical Site Infection, 1999. Centers for Disease Control and Prevention (CDC) Hospital Infection Control Practices Advisory Committee. Am J Infect Control 1999;27:97-132; quiz 3-4; discussion 96.

38. Köckerling F, Bittner R, Jacob D, et al. Do we need 
antibiotic prophylaxis in endoscopic inguinal hernia repair? Results of the Herniamed Registry. Surg Endosc 2015;29:3741-9.

39. Kaul A, Hutfless S, Le H, et al. Staple versus fibrin glue fixation in laparoscopic total extraperitoneal repair of inguinal hernia: a systematic review and meta-analysis. Surg Endosc 2012;26:1269-78.

40. Parshad R, Kumar R, Hazrah P, et al. A randomized comparison of the early outcome of stapled and unstapled techniques of laparoscopic total extraperitoneal inguinal hernia repair. JSLS 2005;9:403-7.

Cite this article as: Hung TY, Wu CC, Chen LS, Kang YN. Safety of two common laparoscopic inguinal herniorrhaphy approaches: an updated systematic review with meta-analysis of randomized clinical trials. Transl Androl Urol 2020;9(5):20072021. doi:10.21037/tau-20-629
41. Smith AI, Royston CM, Sedman PC. Stapled and nonstapled laparoscopic transabdominal preperitoneal (TAPP) inguinal hernia repair. A prospective randomized trial. Surg Endosc 1999;13:804-6.

42. McCormack K, Wake B, Perez J, et al. Laparoscopic surgery for inguinal hernia repair: systematic review of effectiveness and economic evaluation. Health Technol Assess 2005;9:1-203, iii-iv.

43. Higgins JP, Green S. Cochrane handbook for systematic reviews of interventions. John Wiley \& Sons; 2011. 
Cochrane:

(groin hernias $O R$ inguinal hernias $O R$ hernia inguinalis $O R$ hernia inguinalis OR groin hernia OR inguinal hernia) AND (total extra peritoneal OR total extraperitoneal OR tep) AND (TAPP OR trans-abdominal pre-peritoneal OR transabdominal preperitoneal)

\section{$\begin{array}{ll}\text { Cochrane } & \begin{array}{l}\text { Trusted evidence. } \\ \text { Ifformed decisions. } \\ \text { Better health. }\end{array}\end{array}$}

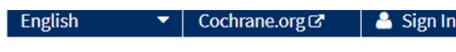

Cochrane Reviews - Trials - Clinical Answers - About - Help -

\section{Advanced Search}

$\sqrt{\text { Search }}$ Search manager Medical terms (MeSH)

Did you know you can now select fields from Search manager using the $S-$ button (next to the search box)?

Search manager lets you add unlimited search lines, view results per line and access the MeSH browser using the new $\mathrm{MeSH} \vee$ button.

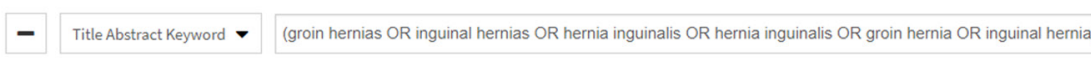

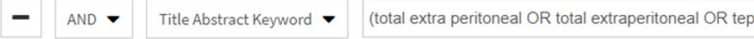

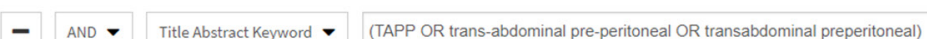

(Word variations have been searche

T search limits $\rightarrow$ send to search manager $Q$ Run search

\section{x clear all}

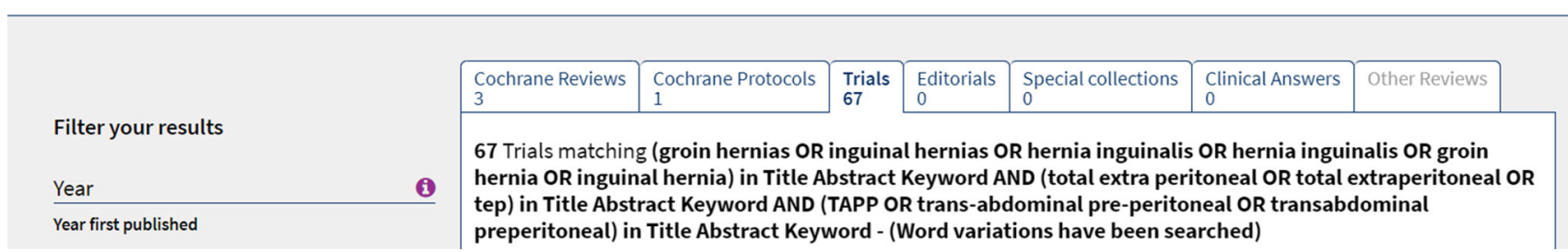

Embase:

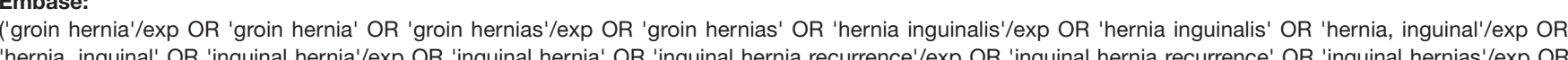

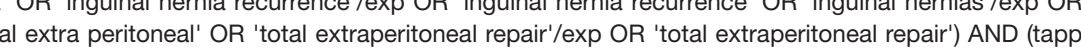
OR 'trans abdominal preperitoneal' OR 'trans abdominal pre peritoneal')

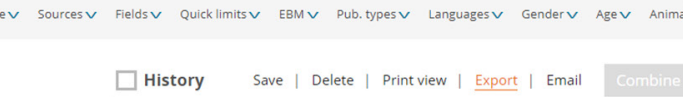

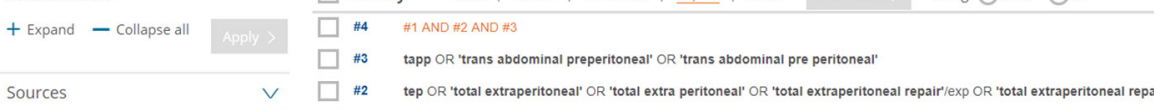

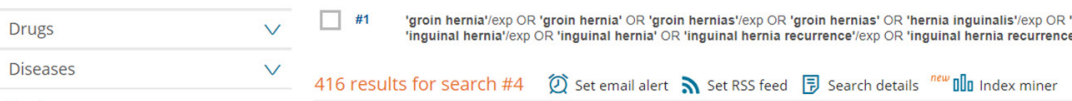

PubMed:
groin hernias $O R$ inguinal hernias $O R$ hernia inguinalis $O R$ hernia inguinalis $O R$ groin hernia $O R$ inguinal hernia) AND (total extra peritoneal OR total (groin hernias OR inguinal hernias OR hernia inguinalls $O R$ hernia inguinalis $O R$ groin hernia $O R$

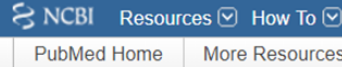

PubMed Advanced Search Builder

Use the builder below to create your search

Edit

Builder

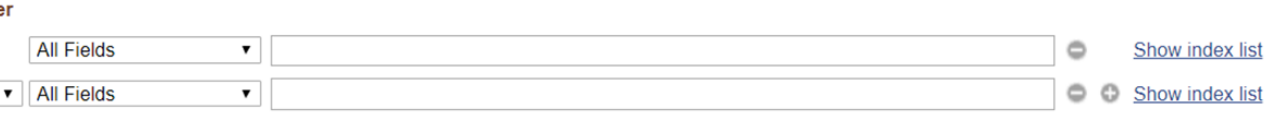

Search or Add to history

\begin{tabular}{|c|c|c|c|c|}
\hline \multirow{2}{*}{ listory } & \multicolumn{4}{|c|}{ Download history. Clear histt } \\
\hline & Add to builder & Query & Items found & Time \\
\hline$\# 4$ & Add & 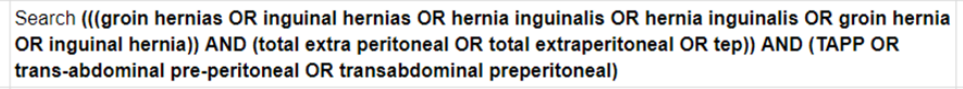 & 256 & 03:50:00 \\
\hline \#3 & A & dominal pre-peritoneal OR transabdominal preperitoneal & 1729 & \\
\hline \#2 & Add & OR total extraperitoneal $\mathrm{C}$ & 28699 & 3:49:42 \\
\hline \#1 & Add & al hernias $O R \mathrm{~h}$. & 17670 & 3:49:35 \\
\hline
\end{tabular}

Web of Science:

作 total extraperitoneal OR tep) AND TOPIC. (TAPP OR trans-abdominal pre-peritoneal OR transabdominal preperitoneal)

Web of Science

1 Clarivate

\section{Results: 317 \\ Did you mean: (TTOPIC: (IIIIroin

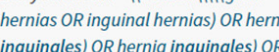

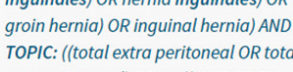

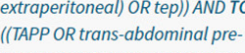 peritoneal) OR transabdomin

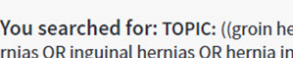

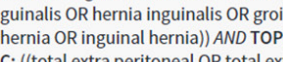

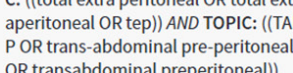

Sort by: Date $[\bar{E}$ Times Cited Usage Count Relevance More -

41 of 32 ।

$$
\square \text { Select rage } \square \text { Export... Add to Marked list }
$$

FIII Analyze Results Long-term follow-up of endoscopic totally extraperitoneal direct inguinal hernia repair using the ion Report

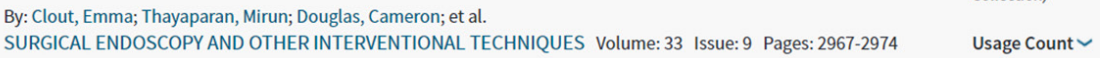

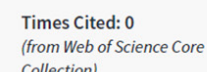
(3) Find TMU Fulltext Full Text from Publisher View Abstract -

Lightweight versus Heayyweight Mesh in Laparoscopic Inguinal Hernia Repair: An Updated Systematic By: Hu, Dan; Huang, Bin; Gao, Lil Ced Early Access: AUG 2019

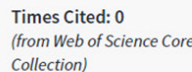




\begin{tabular}{|c|c|c|c|c|c|c|}
\hline Trial & 1 & 2 & 3 & 4 & 5 & 6 \\
\hline Bansal et al. & Low risk & Low risk & High risk & Low risk & Unclear & Low risk \\
\hline Butler et al. & Unclear & Low risk & Low risk & Low risk & Unclear & Low risk \\
\hline Dedemadi et al. & Unclear & Low risk & High risk & Low risk & Low risk & Low risk \\
\hline Gong et al. & Unclear & Unclear & High risk & Low risk & Unclear & Low risk \\
\hline Hamza et al. & Low risk & Low risk & Unclear & Low risk & Unclear & Low risk \\
\hline Jeelani et al. & Unclear & High risk & High risk & Low risk & Low risk & High risk \\
\hline Krishna et al. & Low risk & Low risk & High risk & High risk & Unclear & Low risk \\
\hline Mesci et al. & Unclear & Unclear & High risk & Low risk & Unclear & Low risk \\
\hline Pokorny et al. & Low risk & Low risk & High risk & Low risk & Low risk & Low risk \\
\hline
\end{tabular}

1 sequence generation; 2 allocation concealment; 3 blinding of participants and personnel;

4 blinding of outcome assessment; 5 incomplete outcome data; 6 selective reporting.

Figure S1 Quality assessment. 
$\begin{array}{lll}\text { TEP TAPP Peto Odds Ratio } & \text { Peto Odds Ratio }\end{array}$

Study or Subgroup Events Total Events Total Weight Peto, Fixed, 95\% CI

1.3.1 Haematoma (Patient with primary inguinal hernia)

$\begin{array}{lrrrrrr}\text { Hamza et al 2010 } & 0 & 25 & 1 & 25 & 9.3 \% & 0.14[0.00,6.82] \\ \text { Schrenk et al 1996 } & 0 & 24 & 1 & 28 & 9.2 \% & 0.16[0.00,7.96] \\ \text { Pokorny et al 2008 } & 2 & 36 & 7 & 93 & 63.1 \% & 0.74[0.16,3.33] \\ \text { Gong et al 2011 } & 2 & 52 & 0 & 50 & 18.4 \% & 7.25[0.45,117.60] \\ \text { Subtotal (95\% CI) } & & \mathbf{1 3 7} & & \mathbf{1 9 6} & \mathbf{1 0 0 . 0 \%} & \mathbf{0 . 8 3}[\mathbf{0 . 2 5}, \mathbf{2 . 7 5}]\end{array}$

Total events 4 9

Heterogeneity: $\mathrm{Chi}^{2}=3.86, \mathrm{df}=3(\mathrm{P}=0.28) ; \mathrm{I}^{2}=22 \%$

Test for overall effect: $Z=0.30(P=0.76)$

1.3.2 Haematoma (Involving patient with recurrent inguinal hernia)

$\begin{array}{llllll}\text { Mesci et al } 2012 & 0 & 25 & 0 & 25 & \text { Not estimable } \\ \text { Subtotal (95\% CI) } & & \mathbf{2 5} & & \mathbf{2 5} & \text { Not estimable } \\ \text { Total events } & 0 & & 0 & & \end{array}$

Total events $\quad 0$

Test for overall effect: Not applicable

Total $(95 \%$ CI)

162

Total events 4

Heterogeneity: $\mathrm{Chi}^{2}=3.86, \mathrm{df}=3(\mathrm{P}=0.28) ; \mathrm{I}^{2}=22 \%$

Test for overall effect: $Z=0.30(P=0.76)$

Test for subgroup differences: Not applicable

Figure S2 Forest plot of haematoma.
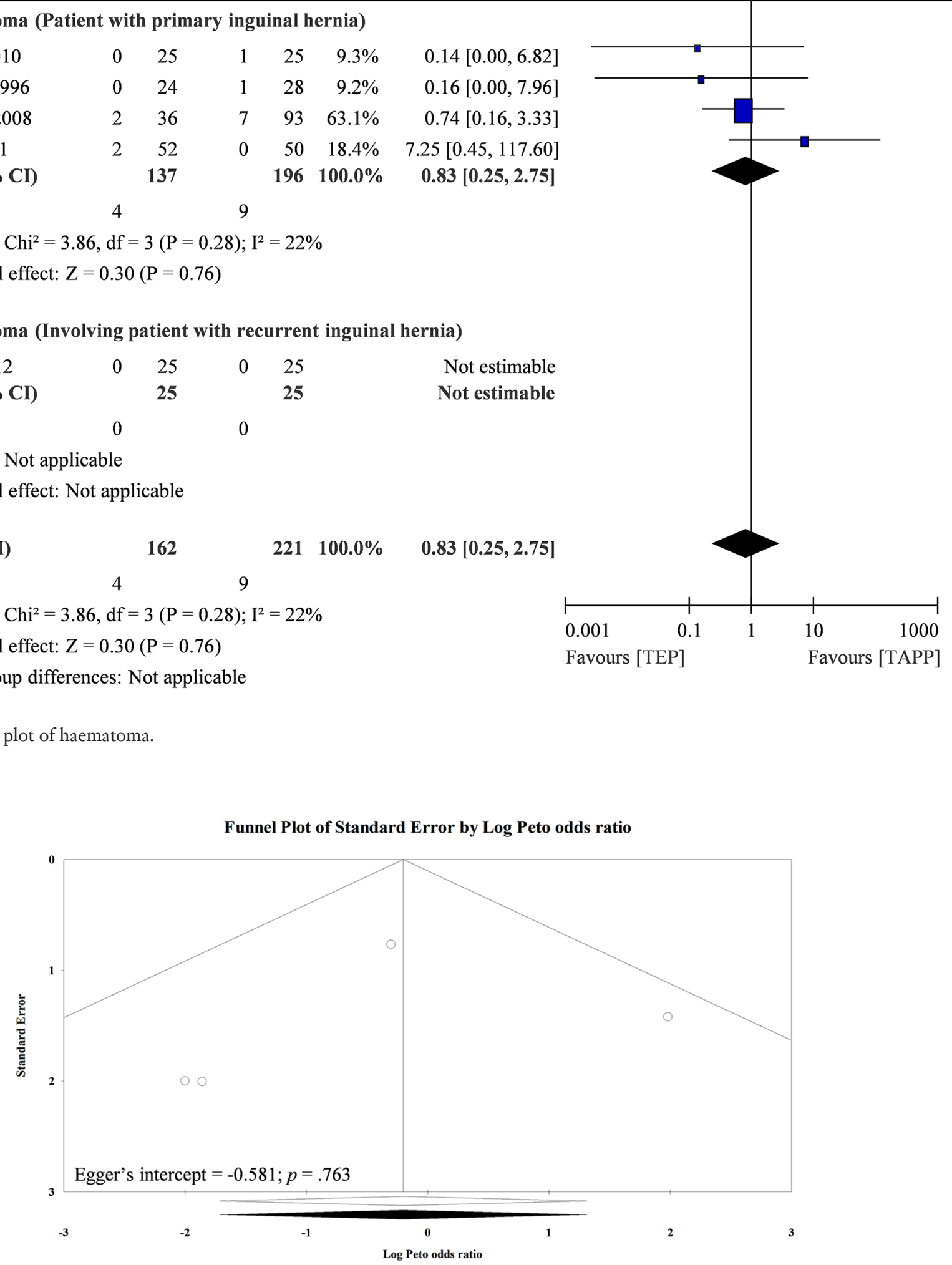

Figure S3 Publication bias test of haematoma. 
TEP TAPP Peto Odds Ratio Peto Odds Ratio

Study or Subgroup Events Total Events Total Weight Peto, Fixed, 95\% CI

Peto, Fixed, 95\% CI

1.4.1 Intra-operative injury (Patient with primary inguinal hernia)

Krishna et al 2012

Schrenk et al 1996

$\begin{array}{rr}0 & 53 \\ 0 & 24 \\ 0 & 36 \\ 3 & 30 \\ 1 & 30 \\ & \mathbf{1 7 3}\end{array}$

$0 \quad 47$

28

Not estimable

Pokorny et al 2008

$0 \quad 28$

793

Not estimable

Sharma et al 2015

130

$48.1 \%$

$0.23[0.04,1.27]$

Jeelani et al 2015

Subtotal (95\% CI)

$0 \quad 30 \quad 9.0 \%$

$2.87[0.38,21.44]$

$22891.1 \%$

$7.39[0.15,372.38]$

$0.84[0.24,2.86]$

Total events

4

8

Heterogeneity: $\mathrm{Chi}^{2}=4.82, \mathrm{df}=2(\mathrm{P}=0.09) ; \mathrm{I}^{2}=58 \%$

Test for overall effect: $Z=0.28(P=0.78)$

1.4.2 Intra-operative injury (Involving patient with recurrent inguinal hernia)

Dedemadi et al 2006

Subtotal (95\% CI)

Total events

Heterogeneity: Not applicable

Test for overall effect: $\mathrm{Z}=1.04(\mathrm{P}=0.30)$

Total (95\% CI)

199

Total events

4

Heterogeneity: $\mathrm{Chi}^{2}=5.64, \mathrm{df}=3(\mathrm{P}=0.13) ; \mathrm{I}^{2}=47 \%$

Test for overall effect: $Z=0.58(P=0.56)$

Test for subgroup differences: $\mathrm{Chi}^{2}=0.82, \mathrm{df}=1(\mathrm{P}=0.36), \mathrm{I}^{2}=0 \%$
$252 \quad 100.0 \% \quad 0.71[0.22,2.28]$ 9

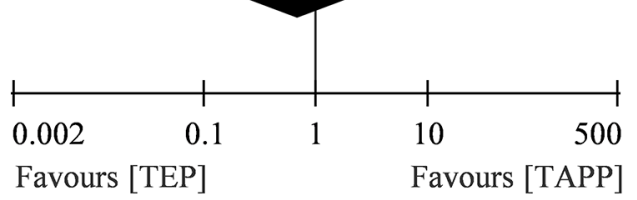

Figure S4 Forest plot of intra-operative injury.

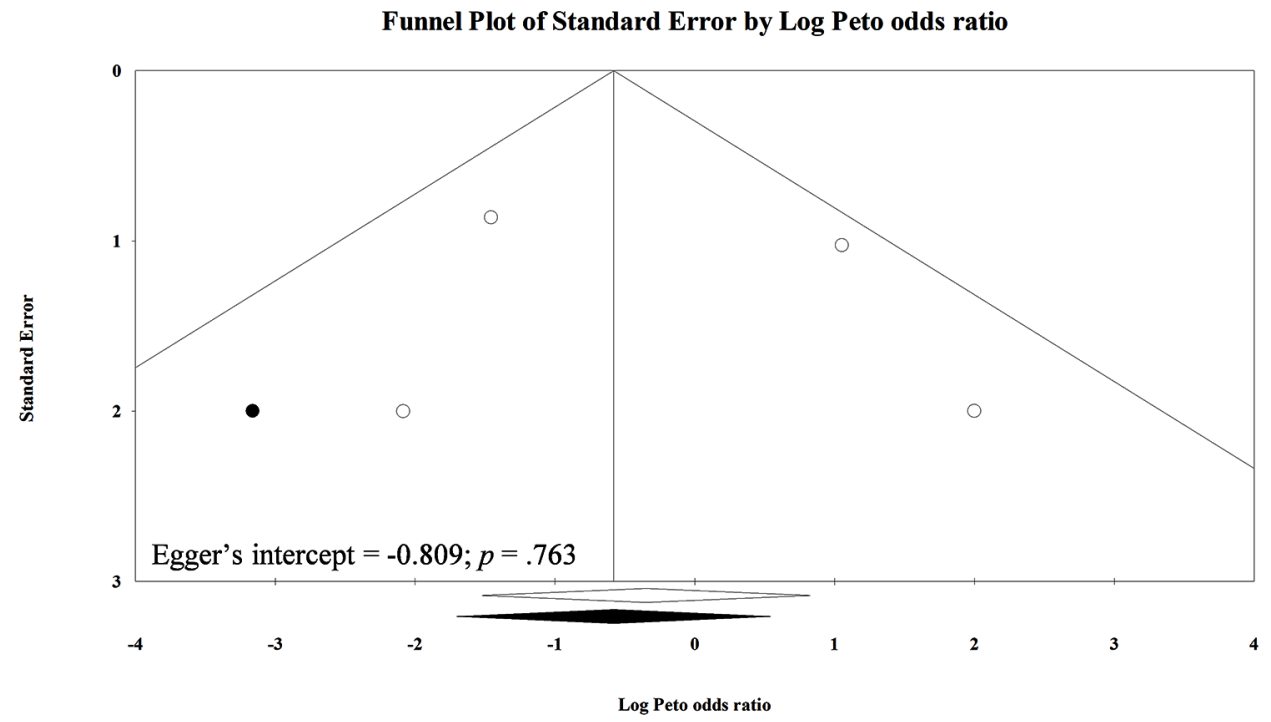

Figure S5 Publication bias test of intra-operative injury. 
$\begin{array}{lll}\text { TEP TAPP Peto Odds Ratio } & \text { Peto Odds Ratio }\end{array}$

Study or Subgroup Events Total Events Total Weight Peto, Fixed, 95\% CI

Peto, Fixed, 95\% CI

1.5.1 Urinary retention (Patient with primary inguinal hernia)

$\begin{array}{lrrrrrr}\text { Gunal et al 2007 } & 1 & 40 & 1 & 39 & 9.4 \% & 0.97[0.06,15.87] \\ \text { Gong et al 2011 } & 4 & 52 & 3 & 50 & 31.3 \% & 1.30[0.28,5.99] \\ \text { Jeelani et al 2015 } & 2 & 30 & 1 & 30 & 13.8 \% & 1.99[0.20,19.94] \\ \text { Pokorny et al 2008 } & 3 & 36 & 3 & 93 & 22.1 \% & 3.14[0.51,19.35] \\ \text { Subtotal (95\% CI) } & & \mathbf{1 5 8} & & \mathbf{2 1 2} & \mathbf{7 6 . 6 \%} & \mathbf{1 . 7 5}[\mathbf{0 . 6 6 , 4 . 6 4}] \\ \text { Total events } & 10 & & \mathbf{8} & & & \end{array}$

Heterogeneity: $\mathrm{Chi}^{2}=0.72, \mathrm{df}=3(\mathrm{P}=0.87) ; \mathrm{I}^{2}=0 \%$

Test for overall effect: $\mathrm{Z}=1.12(\mathrm{P}=0.26)$

1.5.2 Urinary retention (Involving patient with recurrent inguinal hernia)

Mesci et al 2012

Ciftci et al 2015

$2 \quad 25 \quad 9.3 \%$

$0.13[0.01,2.14]$

Dedemadi et al 2006

$\begin{array}{lllll}0 & 30 & 1 & 31 & 4.8 \%\end{array}$

$0.14[0.00,7.05]$

Subtotal (95\% CI)

126

$124 \quad 9.3 \%$

$0.92[0.06,15.20]$

81

$80 \quad 23.4 \%$

$0.29[0.05,1.68]$

Total events

1

4

Heterogeneity: $\mathrm{Chi}^{2}=1.10, \mathrm{df}=2(\mathrm{P}=0.58) ; \mathrm{I}^{2}=0 \%$

Test for overall effect: $Z=1.38(P=0.17)$

\section{Total (95\% CI)}

Total events

239

Heterogeneity: $\mathrm{Chi}^{2}=4.89, \mathrm{df}=6(\mathrm{P}=0.56) ; \mathrm{I}^{2}=0 \%$

Test for overall effect: $\mathrm{Z}=0.31(\mathrm{P}=0.76)$

Test for subgroup differences: $\mathrm{Chi}^{2}=3.06, \mathrm{df}=1(\mathrm{P}=0.08), \mathrm{I}^{2}=67.4 \%$

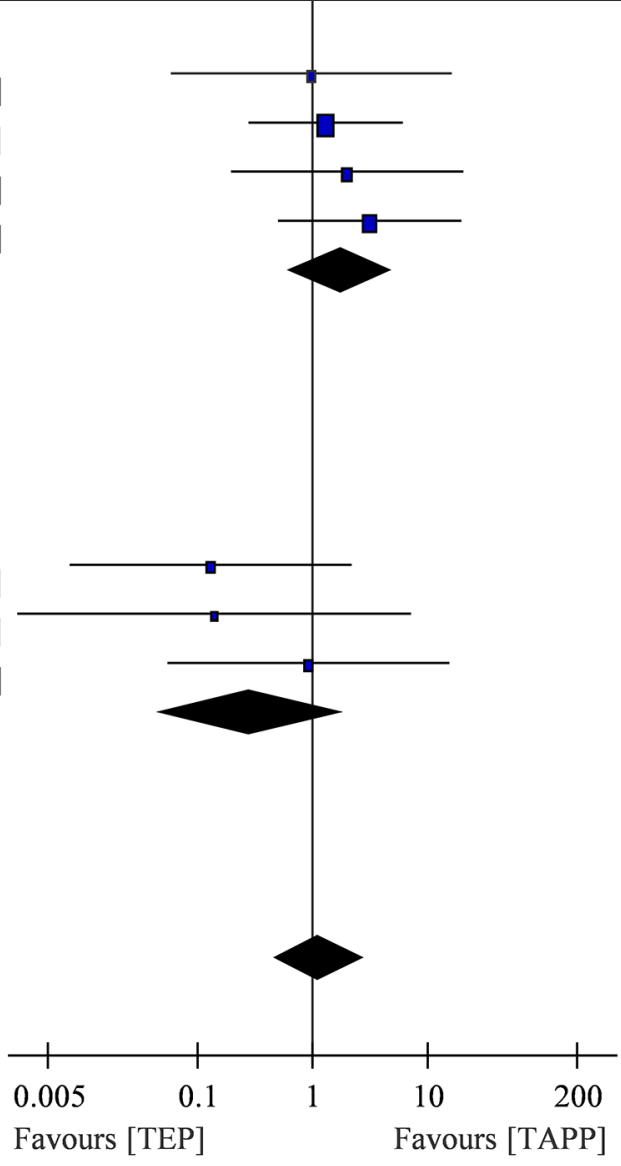

Figure S6 Forest plot of urinary retention.

Funnel Plot of Standard Error by Log Peto odds ratio

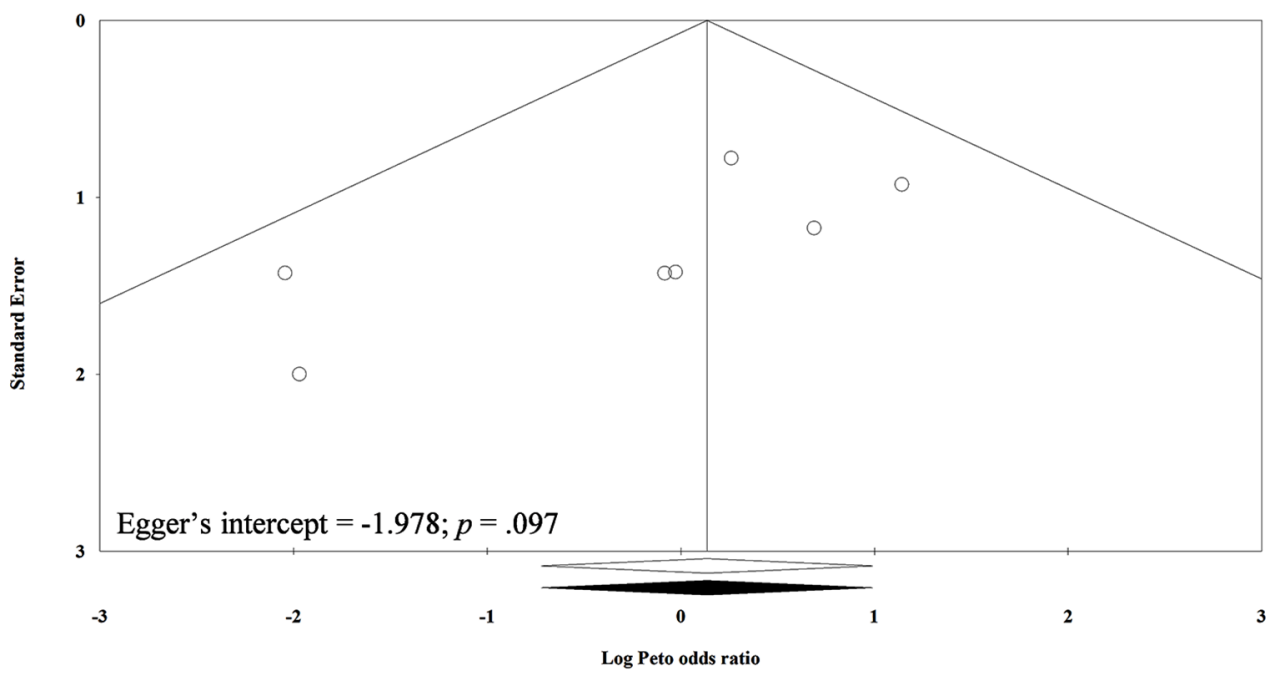

Figure S7 Publication bias test of urinary retention. 
TEP TAPP Peto Odds Ratio Peto Odds Ratio

Study or Subgroup Events Total Events Total Weight Peto, Fixed, 95\% CI

1.6.1 Epigastric vessel bleeding (Patient with primary inguinal hernia)

Krishna et al 2012

Gunal et al 2007

Sharma et al 2015

Subtotal $(95 \%$ CI)

Total events

Heterogeneity: $\mathrm{Chi}^{2}=1.19, \mathrm{df}=1(\mathrm{P}=0.28) ; \mathrm{I}^{2}=16 \%$

Test for overall effect: $\mathrm{Z}=0.32(\mathrm{P}=0.75)$

1.6.2 Epigastric vessel bleeding (Involving patient with recurrent inguinal hernia)
Dedemadi et al 2006

Subtotal (95\% CI)

Total events

0

26

26

0

Heterogeneity: Not applicable

Test for overall effect: $\mathrm{Z}=1.04(\mathrm{P}=0.30)$

Total (95\% CI)

149

Total events 5

Heterogeneity: $\mathrm{Chi}^{2}=2.37, \mathrm{df}=2(\mathrm{P}=0.31) ; \mathrm{I}^{2}=16 \%$

Test for overall effect: $Z=0.03(P=0.97)$

Test for subgroup differences: $\mathrm{Chi}^{2}=1.18, \mathrm{df}=1(\mathrm{P}=0.28), \mathrm{I}^{2}=15.6 \%$

Figure S8 Forest plot of epigastric vessel bleeding.

$24 \quad 10.5 \%$

1

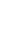

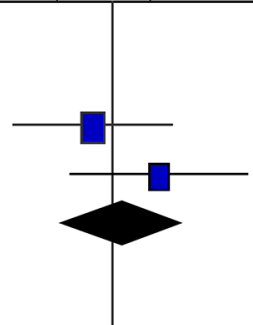

Not estimable

$0.64[0.11,3.86]$

$2.87[0.38,21.44]$

$1.25[0.33,4.76]$
$0.12[0.00,6.29]$

$0.12[0.00,6.29]$

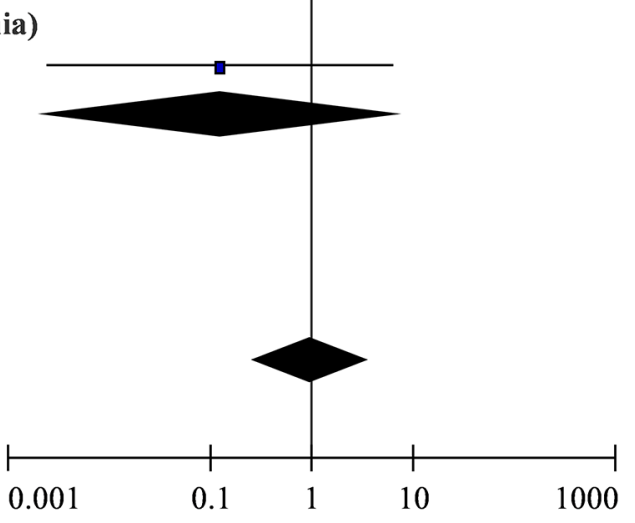

Favours [TEP]

Funnel Plot of Standard Error by Log Peto odds ratio

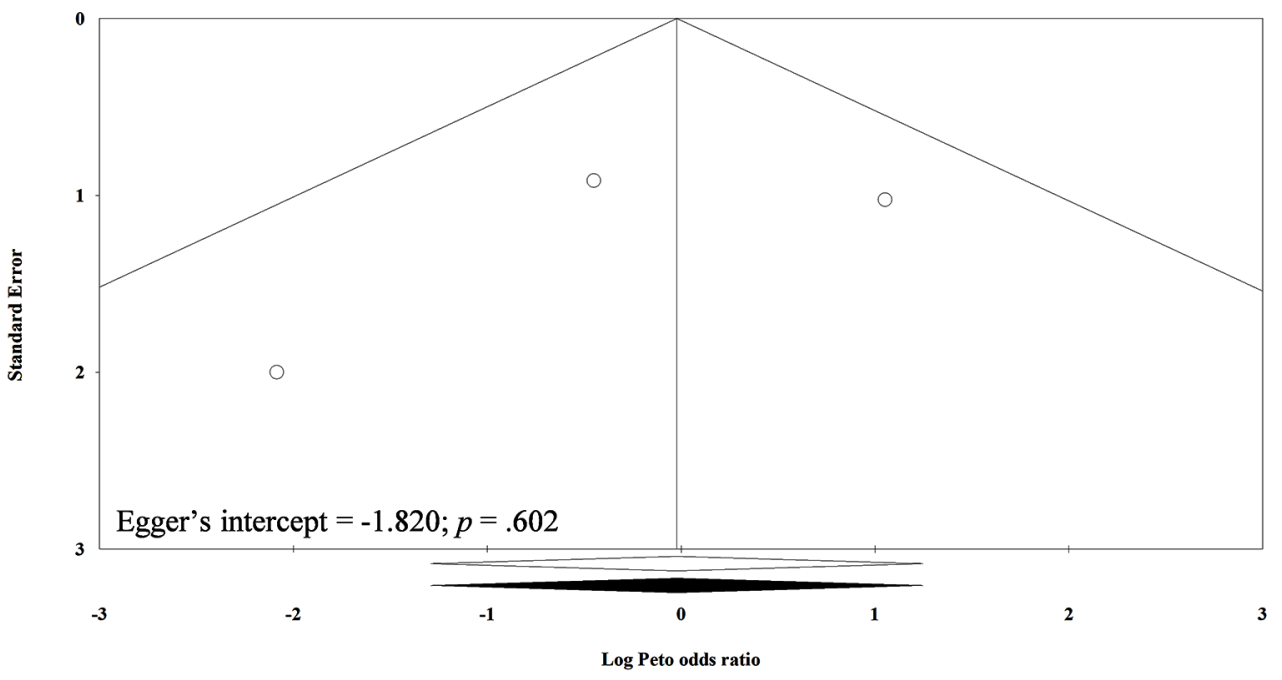

Figure S9 Publication bias test of epigastric vessel bleeding. 


\section{TEP TAPP Peto Odds Ratio Peto Odds Ratio}

Study or Subgroup Events Total Events Total Weight Peto, Fixed, 95\% CI $\quad$ Peto, Fixed, 95\% CI

1.7.1 Wound infection (Patient with primary inguinal hernia)

$\begin{array}{lrrrrrr}\text { Butler et al 2007 } & 0 & 22 & 0 & 22 & & \text { Not estimable } \\ \text { Pokorny et al 2008 } & 0 & 36 & 0 & 93 & & \text { Not estimable } \\ \text { Hamza et al 2010 } & 0 & 25 & 1 & 25 & 5.1 \% & 0.14[0.00,6.82] \\ \text { Krishna et al 2012 } & 1 & 53 & 3 & 47 & 19.9 \% & 0.31[0.04,2.30] \\ \text { Gong et al 2011 } & 1 & 52 & 3 & 50 & 19.9 \% & 0.34[0.05,2.51] \\ \text { Sharma et al 2015 } & 1 & 30 & 2 & 30 & 14.9 \% & 0.50[0.05,5.02] \\ \text { Bansal et al 2013 } & 3 & 160 & 5 & 154 & 40.2 \% & 0.58[0.14,2.34] \\ \text { Subtotal (95\% CI) } & & 378 & & 421 & 100.0 \% & 0.42[0.17,1.02] \\ \text { Total events } & 6 & & 14 & & & \end{array}$

Heterogeneity: $\mathrm{Chi}^{2}=0.66, \mathrm{df}=4(\mathrm{P}=0.96) ; \mathrm{I}^{2}=0 \%$

Test for overall effect: $Z=1.92(\mathrm{P}=0.05)$

1.7.2 Wound infection (Involving patient with recurrent inguinal hernia)

$\begin{array}{llllll}\text { Mesci et al 2012 } & 0 & 25 & 0 & 25 & \text { Not estimable } \\ \text { Dedemadi et al 2006 } & 0 & 26 & 0 & 24 & \text { Not estimable } \\ \text { Subtotal (95\% CI) } & & \mathbf{5 1} & & \mathbf{4 9} & \text { Not estimable } \\ \text { Total events } & 0 & & 0 & & \end{array}$

Heterogeneity: Not applicable

Test for overall effect: Not applicable

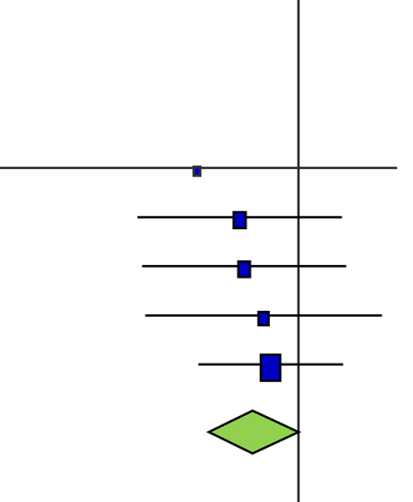

